\title{
N-Reactor Charge-Discharge System Analysis
}

\author{
R. D. Tokarz \\ G. D. Marr \\ J. F. Nesbitt
}

September 1982.

Prepared for

UNC Nuclear Industries

Productivity Improvement Program

Pacific Northwest Laboratory

Operated for the U.S. Department of Energy

by Battelle Memorial Institute 


\section{DISCLAIMER}

This report was prepared as an account of work sponsored by an agency of the United States Government. Neither the United States Government nor any agency thereof, nor any of their employees, makes any warranty, express or implied, or assumes any legal liability or responsibility for the accuracy, completeness, or usefulness of any information, apparatus, product, or process disclosed, or represents that its use would not infringe privately owned rights. Reference herein to any specific commercial product, process, or service by trade name, trademark, manufacturer, or otherwise, does not necessarily constitute or imply its endorsement, recommendation, or favoring by the United States Government or any agency thereof. The views and opinions of authors expressed herein do not necessarily state or reflect those of the United States Government or any agency thereof.

\section{PACIFIC NORTHWEST LABORATORY operated by \\ BATTELLE \\ for the \\ UNITED STATES DEPARTMENT OF ENERGY under Contract DE-AC06-76RLO 1830}

\begin{tabular}{|c|c|}
\hline \multicolumn{2}{|c|}{$\begin{array}{c}\text { National Technical Information Service } \\
\text { United States Department of Commerce } \\
5285 \text { Port Royal Road } \\
\text { Springfield, Virginia } 22151\end{array}$} \\
\hline \multicolumn{2}{|c|}{$\begin{array}{l}\text { NTIS Price Codes } \\
\text { Microfiche A01 }\end{array}$} \\
\hline \multicolumn{2}{|c|}{ Printed Copy } \\
\hline Pages & $\begin{array}{l}\text { Price } \\
\text { Codes }\end{array}$ \\
\hline $001-025$ & $\mathrm{~A} 02$ \\
\hline $026-050$ & $\mathrm{~A} 03$ \\
\hline $051-075$ & A04 \\
\hline $076-100$ & A05 \\
\hline $101-125$ & $A 06$ \\
\hline $126-150$ & $\mathrm{~A} 07$ \\
\hline $151-175$ & $\mathrm{~A} 0 \mathrm{~B}$ \\
\hline $176-200$ & $\mathrm{~A} 09$ \\
\hline $201-225$ & $\mathrm{~A} 010$ \\
\hline $226-250$ & A011 \\
\hline $251-275$ & A 012 \\
\hline $276-300$ & $A 013$ \\
\hline
\end{tabular}


PNL-4314

UC -2

N-REACTOR CHARGE-DI SCHARGE

SYSTEM ANALYSIS
R. D. Tokarz
G. D. Marr
J. F. Nesbitt

September 1982

Prepared for

UNC Nuclear Industries

Productivity Improvement Program

Pacific Northwest Laboratory

Richland, Washington 99352 


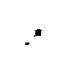

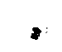

4 


\section{SUMMARY}

This report documents an analysis of the existing systems in the N-Reactor fuel flow path. It recommends equipment improvements and changes in that path to allow the charge-discharge rates to be increased to 500 tubes per outage without increasing reactor outage time.

The estimated program cost of $\$ 14$ million is projected over an estimated 3-year period. It does not include costs detailed as part of the existing restoration program or any costs that are considered as normal maintenance. The recommendations contained in this report provide a direction and goal for every critical aspect of the fuel flow path. The way in which these recommendations are implemented may greatly affect the schedule and costs.

Previous studies by UNC have shown that enhanced fuel element handling has the potential of increasing productivity by 33 days at a cost benefit estimated at $\$ 18$ million per year. Enhanced fuel handling provides the greatest potential for productivity improvement of any of the areas considered in these studies.

Increasing the number of tubes discharged during each outage can directly increase in annual production. However, increasing the number of tubes discharged will not improve production if it significantly increases the outage time required. At the same time, efficiencies must be included into the fuel handling operation so that personnel radiation exposure remains within established limits. These two factors require improvements in equipment and machines to complete charge-discharges at higher rates while minimizing radiation exposure to operators.

Based on the charge-discharge system analysis, significant modifications are recommended in four main areas:

1. fuel storage and transport - An action plan that will lead to more efficient storage and timely transport of fuel from the 300 Area to achieve 500-tube charge-discharge is suggested. 
2. monotube loader and charging machine - Specific design improvements that will permit more reliable and efficient charge-discharge operations are detailed.

3. C\&D elevators and ancillary equipment - Suggested design changes in elevator tooling, tube caps, and the tip-off are described and diagrammed. Procedural changes involving the use of robotic devices are also presented.

4. fast cart and basin operations - Recommendations include replacing the fast cart and modifying basin use patterns to reduce fuel damage ano expedite basin operation and storage activities.

Implementing the plans and recommendations presented in this report will improve all of the equipment involved in the charge-discharge operations. It will also result in reduced radiation exposure to UNC personnel, increased reactor charging rates, longer operating periods by increasing the number of tubes charged during each outage, and an increased number of reactor operating days each year. 


\section{ACKNOWLEDGMENTS}

The authors would like to acknowledge the cooperation of a host of individuals at UNC Nuclear Industries for their patient assistance in providing details of present and past charge-discharge operations at $\mathrm{N}$-Reactor. 


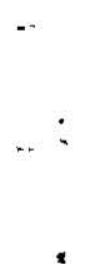

$r$ 


\section{CONTENTS}

SUMMARY

ACKNOWL EDGMENTS

1.0 INTRODUCTION

2.0 ANALYSIS OF SYSTEMS TO ACHIEVE 500 TUBE CHARGE-DISCHARGE . . 3

2.1 UNIRRADIATED FUEL STORAGE AND HANDLING $\quad . \quad . \quad . \quad$. $\quad$. 3

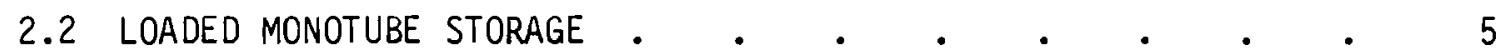

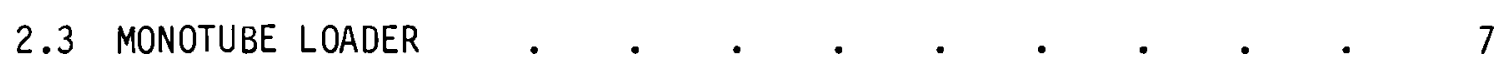

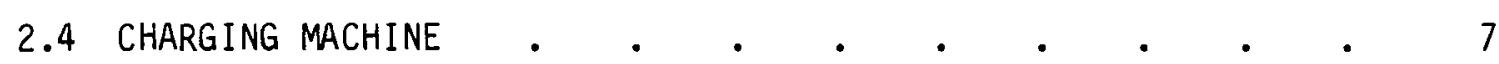

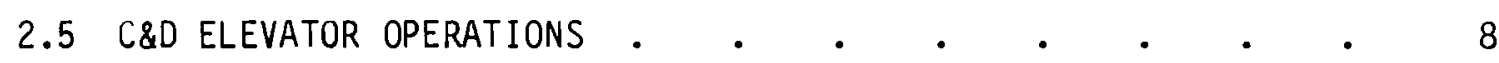

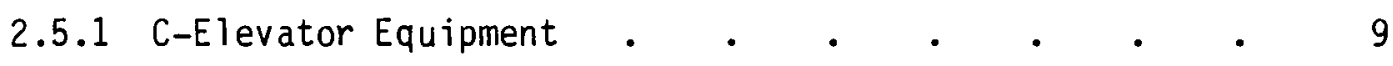

2.5.2 D-Elevator Equipment . . . . . . . . . . 11

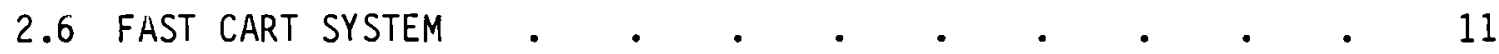

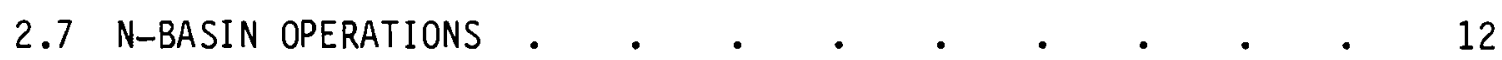

2.7.1 Storage Delays . . . . . . . . . . 13

2.7.2 MK I Canister Design . . . . . . . . 13

2.7.3 Casks and Well Cars . . . . . . . . . . 14

2.7.4 Recanning Operations . . . . . . . . . . . 14

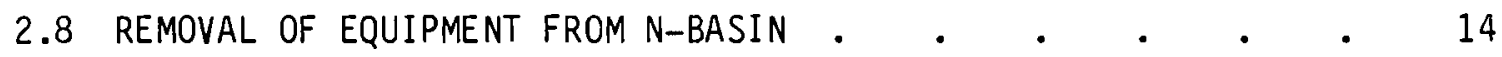

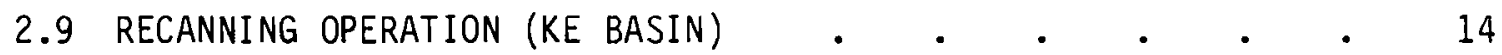

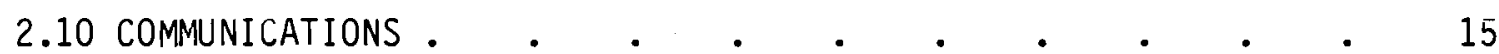

3.0 SPECIFIC TASK RECOMMENDATIONS •

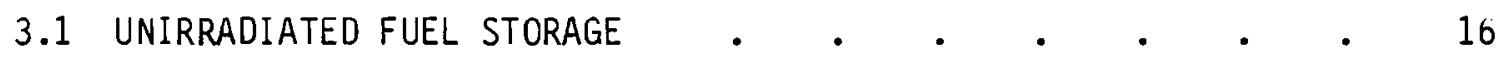

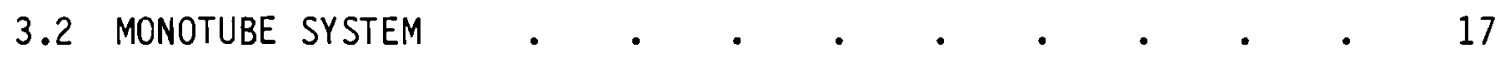

3.3 CHARGE MACHINE REPLACEMENT.$\quad$. . . . . . . . 20

3.3.1 Drive Rollers . . . . . . . . . . . . 21

3.3.2 Transfer Arm System . . . . . . . . 21

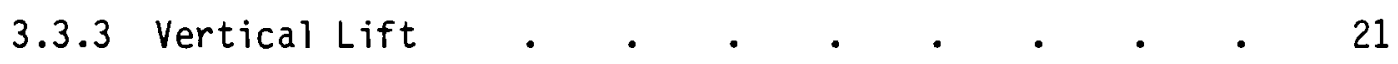

3.3.4 Cross Travel Drive System . . . . • • . 21

3.3.5 Long-Term Resolution of the W-Elevator Failures . . 22

3.3.6 Fuel Charging System • • • • • • • 22 


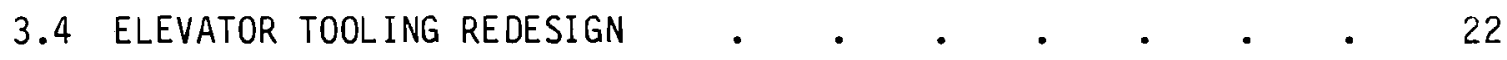

3.4.1 Air Wrenches . . . . . . . . . . . . 22

3.4 .2 Breaker Bars. . . . . . . . . . . 23

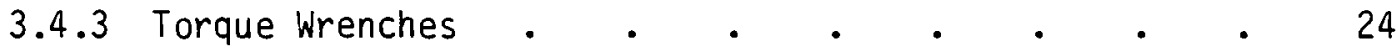

3.4.4 Process Tube Caps and Removal/Installation . . . 24 Tools

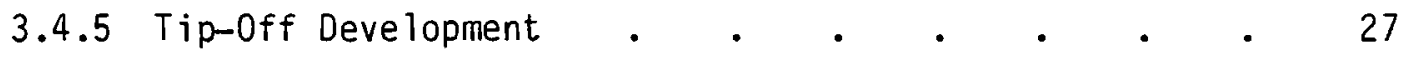

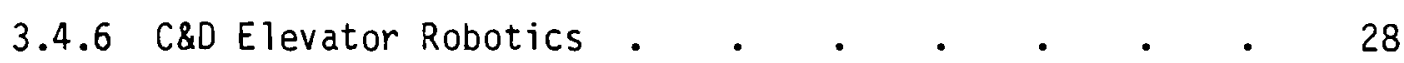

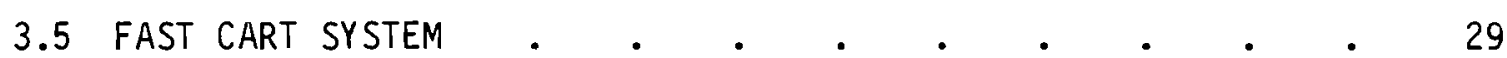

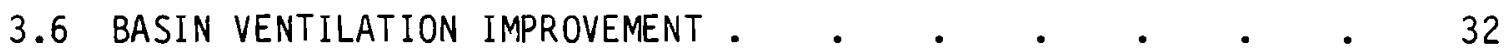

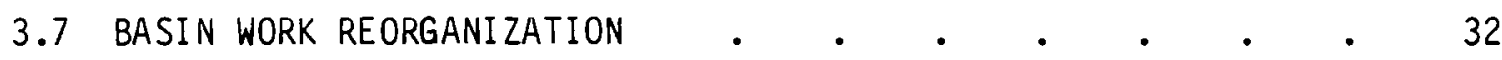

3.7.1 Basket Utilization Modification . $\quad . \quad$ • $\quad . \quad$ • 35

3.7 .2 Canister Redesign . . . . . . . . . . . 35

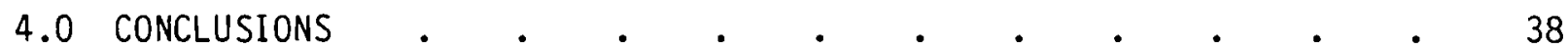

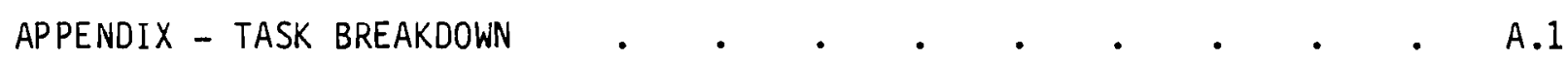


1 Conceptual Design for Monotube Loading and Additional . $\quad$ - 19 Loaded Monotube Storage to Obtain 500 Tube Charge-Discharge

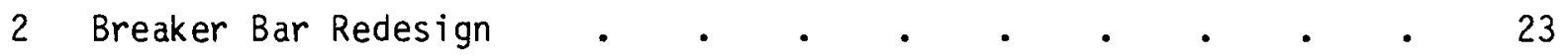

3 Conceptual Design for Improved Process Tube Cap . • • • $\quad$ - 25

4 Conceptual Design for Improved Process Tube Cap . . . . . 26

5 Conceptual Design for an Irradiated Fuel Conveyor . . . . . 31

6 Current Empty and Ful1 Basket Arrangement . . . . . . . 33

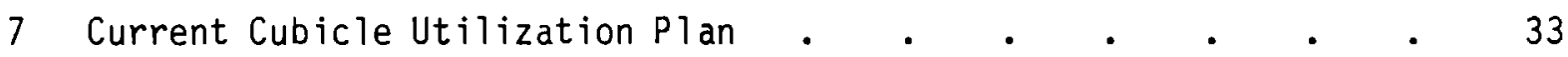

8 Proposed Basket Arrangement for 333-Tube Discharge . . . . 34

9 Proposed Basket Arrangement for 500-Tube Discharge . . . 34

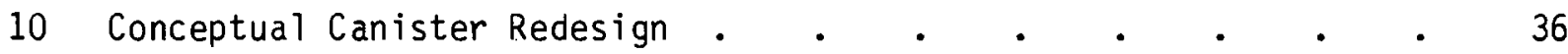




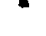




\section{N-REACTOR CHARGE-DISCHARGE \\ SYSTEM ANALYSIS}

\subsection{INTRODUCTION}

Implementation of the 6 percent program at $\mathrm{N}$-Reactor requires seven to eight charge-discharges per year. A significant increase in productivity can be realized by reducing the number of outages per year through increased batch sizes during charge-discharge. If the number of tubes charged can be increased without extending the outage time, then this represents an additional incremental improvement in production. Increasing charge-discharge rates from the current $1 / 4$ reactor per outage $c$ an best be managed by incremental increases of $1 / 3$ or $1 / 2$ reactor.

The success of these increases depends primarily upon the various components and systems composing the entire fuel flow path. By identifying critical path problems that exist at the current charge rates and then projecting these limitations to higher charge rates, changes necessary to achieve the new charge rates can be identified.

This study was conducted for UNC Nuclear Industries by the Pacific Northwest Laboratory (PNL). The scope of this effort encompassed observation and analysis of the current equipment and procedures involved in the fuel flow path, from unirradiated fuel received at $\mathrm{N}$-Reactor to final delivery at the PUREX facility. The study objective was to recommend equipment design improvements, personnel practice modifications, or proceduréal changes that will enable UNC Nuclear Industries to achieve the goal of increasing chargedischarge rates while minimizing personnel radiation exposure. The study sought to recommend systems capable of achieving charging rates compatible with the requirements for 500 tube charge-discharges at 10 tubes per hour.

The 6 percent program is underway. However, several other programs being considered could adversely impact the charge-discharge operations. This study has analyzed the basic impact of implementing these options by providing 
recommendations that are broadly scoped so that the improved systems will not become critical path items if other options are later introduced.

In Section 2.0, the fuel flow path system observations are analyzed. General suggestions for solving the noted problems are also presented. Section 3.0 presents the specific recommendations for modifying equipment and procedures. The study conclusion are presented in Section 4.0 The Appendix contains detailed task breakdowns, as well as cost and scheaule estimates. 


\subsection{ANALYSIS OF SYSTEMS TO ACHIEVE 500 TUBE CHARGE-DISCHARGES}

Assessments and observations of each fuel flow path component are discussed in this section. General suggestions for rectifying the noted problem areas are also made here.

\subsection{UNIRRADIATED FUEL STORAGE AND HANDLING}

If the number of tube charges during a single outage is increased from the present 260 tubes ( $1 / 4$ reactor), this increase will impact how fast the tuel will need to be shipped from the 300 Area; where and how the fuel can be stored in 105-N; and when, where, and how the required number of monotubes can be loaded with fuel and stored. To assure sufficient available fuel at 105-N as required for preoutage and charge-discharge activities for a 333-tube ( $1 / 3$ reactor) outage, only a few changes in practices or procedures will be required. No major equipment changes or additions are necessary. However, before it will be possible to charge 500 ( $1 / 2$ reactor) tubes in an outage, certain equipment changes and additions will need to be implemented. Also, practices and procedures will need to be altered.

Currently, the only secured space in the 105-N Building for storage of unirradiated fuel as received from the 300 Area is Room 182. Although designed to contain up to 200 metric tons (over 500 tube charges) of fuel, this amount cannot be stored there due to limits pertaining to fuel enrichments and the variations in fuel element lengths. This reduces the amount of fuel available for each outage.

The usable storage in Room 182 could be increaseo in two ways: 1) eliminate or reduce inactive fuel storage needs and expand usable storage to five rows of boxes, two high and sixteen boxes long, or 2) reduce inactive storage needs and expand the usable storage to six rows of boxes, two high and fifteen boxes long. Either option would allow storing sufficient fuel to charge at least 333 tubes. These arrangements must be evaluated analytically in a validated criticality computer code to assure that the boxed fuel is viable in the undamaged, as well as in destroyed and disarrayed, conditions. A specific criticality study should be initiated as soon as possible to determine if either approach is acceptable. 
Another area in 105-N used for limited, short-term storage of fuel in boxes is the Metal Preparation Room. With some impact on current activities (e.g., storage of empty fuel boxes and boxes of new spacers and personnel traffic through Room 181), boxed fuel could be stored on the west side of the room. Considering current criticality limits, up to 96 boxes of fuel could be stored here. For an average or nominal variation in fuel lengths, this would provide fuel for at least another 200 tubes. However, if Room 181 were to be used as a permanent fuel storage area, various aspects would have to be considered, evaluated, and incorporated into the existing procedures and mode of operations.

Although adaitional security systems and provisions have recently been instituted around $105-\mathrm{N}$, the security requirements for the storage of fuel elements in the building (i.e., in special wooden boxes in a locked and sealed room or loaded into monotubes and stored in Room 29) have not been changed. The addition of adequate locks and provisions for seals on the aoors into Room 181 would render the room acceptable and approved for long-term storage of fissile materials in the form of unirradiated fuel.

However, better use of the secured storage space in Room 182 and supplemental fuel supply deliveries from the 300 Area could ensure enough fuel on hand to load up to 500 monotubes. Up to 26 boxes of fuel can be shipped in a van. The current van can usually transport and deliver enough fuel to $105-\mathrm{N}$ to load up to 50 tubes less than 24 hours after being requested. (a) Only one van at Hanford is currently dedicated to transporting fuel from the 300 Area to $105-\mathrm{N}$.

This fuel storage problem is intimately tied to the monotube storage problem. If a solution can be found that allows loading an additional 140 monotubes during the reactor operating perioa, then the unirradiated fuel storage problems would be solved, because the reactor operating period is long enough to allow spaced shipments of fuel from 300 Area. If, however, the solution

(a) Prior to a recent outage, four fuel deliveries were scheduled and received at 105- $N$ without impacting the monotubes loading. 
to the monotube storage problem is to recharge monotubes during the reactor outage (split charging), then the unirradiated fuel storage problem is limited to handling the additional fuel during the outage.

\subsection{LOADED MONOTUBE STORAGE}

Racks installed on both the east and west walls of Room 29 (W-Elevator) can store 360 loaded monotubes and an additional 40 empty monotubes. The monotube storage pattern is five tubes wide on each side of the W-Elevator at 40 (36 usable with the charge machine) different levels. The vertical spacing of the monotubes is 9 inches center-to-center, and they are essentially spread over the combined vertical travel of the W-Elevator and the charging machine.

Expansion alternatives for the monotube storage capacity in Room 29 have been evaluated. It is not feasible to add to the number of tubes stored on each row. This change would require not only a redesign and installation of new racks, but would necessitate the removal of several inches from each side of the elevator platform and relocation of numerous items. In addition, the charging machine would have to be redesigned significantly before it could pick up and handle six tubes at a time. Existing electrical conduit, junction boxes, and other appurtenances below and above the current racks would limit any additional rows.

Room 181 has sufficient floor area and height to load and/or store a limited number of full length monotubes. However, if this work area were to be used for this activity, changes and additions would be required in the equipment and procedures to load and handle monotubes. There would be a definite limit on the potential available space for bcxed fuel and other material, as well as space for and access to the monotube loader.

One way to supplement the available loaded monotube storage along the two sides of the $W$-Elevator would be to use racks capable of holding up to 25 loaded monotubes each, mounted on a mechanically-actuated chart. The monotubes on these carts could be loaded by the existing monotube loader while a cart is located on the W-Elevator. One loaded cart could be stored on each side of the $W$-Elevator while two other loaded carts would be removed from the $W$-Elevator and stored in the Metal Preparation Room (Room 181). These two carts would be 
interchanged with the two originally located on the W-Elevator after their monotubes had been emptied. To reduce W-Elevator travel and to compensate for limits on the charge machine access, the monotubes on these carts should be used to charge process tubes in the lower center of the reactor.

This approach would require fabricating four carts, each capable of supporting and transporting 25 monotubes, 53 feet 7 inches long with a total loading of about 30,000 pounds. The carts could be provided with racks that would have an arrangement and spacing similar to the existing wall racks. Two carts would be opposite-handed to the other two. Each cart must contain provisions for, or be capable of, being moved

- on and off W-Elevator

- east and west on the W-Elevator

- north and south on the $W$-Elevator.

Also, means must be provided on each cart to raise and lower the racks so each layer of tubes is accessible to the charge machine pickup arms, and to mate and hold a selected tube to the monotube loader. A cart design that could fulfill all of the above needs further identification to assure that it could be made to work within all of the existing limitations. This concept also requires that Room 181 become a controlled-access radiation zone. Because of the complexities of the problems associated with this concept, it is not a recommended solution.

The most viable solution to this difficult problem would be to aesign a new monotube loader. This loader would load five monotubes which are being held in the pickup position on the charge machine. It would also be capable of loading special monotubes that are loaded, stored, and unloaded while remaining in Room 181. This concept would allow more rapid loading of the 360 monotubes in Room 29, followed by loading of 140 special monotubes in Room 181. Both tasks would be accomplished during reactor operating periods. During the outage, the monotube loader could be repositioned to accept the 140 special monotubes and to transfer the fuel loaded in these tubes into empty tubes on the charge machine. This system would maintain isolation of 
the controlled access zone to Room 29 while permitting the storage of additional monotubes in Room 181. It also provides for the rapid transfer of this fuel to the charge machine to achieve 500-tube charge-discharge. The existing charge machine could be used after one minor modification. To load five monotubes while on the pickup position, a backing plate must be adoed to the charge machine. This plate would be placed at the reactor face end of the five monotubes so that, when the fuel charges are pushed into them, the monotubes are held stationary against it.

\subsection{MONOTUBE LOADER}

At the monotube loader, individual unirradiated fuel elements undergo examination and enrichment-counting. The monotube loader is also the conveyance for inserting a full tube charge into a monotube. The loader consists of a fuel-handling table connected to a conveyor tray. The fuel is placed on the table and examined for various defects. The appropriate spacers and fuel are then transferred, one at a time, to the conveyor where they advance past the enrichment counter. When a complete tube charge is on the conveyor, the total length of the charge and the individual number of fuel elements are visually rechecked. Then the loader drives entire charge into a monotube. This system is adequate for the current 260-tube charge-discharge operations and for increases to 333-tube charge-discharges. It will not work for 500-tube chargedischarge operations because of the requirements to charge and store additional monotubes outside Room 29. It could be used for 500-tube charge-discharge operations if these operations were accomplished by split-charging during the reactor outage. However, the split-charging tends to reduce productivity improvements by requiring longer outage periods.

\subsection{CHARGING MACHINE}

The charge machine loads charged fuel monotubes from racks located on either side of the $W-E l$ levator through charge holes in the barrier wall into the reactor tube nozzles. It then charges fresh fuel into the reactor while simultaneously discharging irradiated fuel out the reactor rear face by water pressure. The machine traverses the entire width of the elevator by hydraulically-driven spur gears engaging racks attached to the elevator floor. In 
addition to the elevator's vertical motion, the charge machine can be raised or lowered approximately 27 inches to align tubes and to pick up the monotubes from the wall racks. The tubes are picked up and retrieved by transfer arms, which can retrieve five monotubes at a time from either wall. The monotubes are raised from the transfer arms, after being centered on the platform, by hydraulically-actuated rollers. Delivery through the barrier wall charge hole and into the reactor nozzle is achieved by driving one to three sets of rollers opposed by stationary idler rollers pressed against the monotube. When the tube is within a few inches of the reactor nozzle, a cone-shaped nozzle at the rear of the monotube engages the monotube and drives it against the process tube, thereby sealing both ends of the monotube. Water pressure is then applied to drive the fuel from the monotube into the reactor.

When operating properly, the charging machine is capable of charging 40 tubes per hour, a quantity more than sufficient to remove it from the critical path of the charge-discharge process. Currently, nowever, the operator must frequently leave the control console to effect repairs or to physically assist the loading process. The current drive rollers frequently slip when the tube enters the barrier wall charge hole, necessitating operator assistance. This problem appears to be a major cause of delays in the charging process.

Aligning the monotube with a charge hole is accomplished by centering a collimated visible light beam on a dot painted on the wall corresponding to the desired charge hole number. This sighting system appears adequate although it is currently misaligned. Vertical alignment is readily cone by raising or lowering the charge platform. Horizontal alignment is considerably more difficult. The entire machine must be moved, and overshoot of ten occurs. Various travel limits are imposed by photocells or microswitches.

\subsection{C\&D ELEVATOR OPERATIONS}

Personnel radiation exposure during charge-discharge is very high on the front and rear elevators. Operators must perform their work in fult raingear. Direct skin contamination occurs in these work areas nevertheless because operators are subject to contaminated water spraying. Improvements in work 
procedures, machinery, and equipment can contribute substantially toward reducing personnel radiation exposure and skin contamination while simultaneously hastening the charge-discharge effort. A primary goal of this productivity improvement program should be to reduce or eliminate employees' direct contact with the contaminated reactor water.

\subsubsection{C-Elevator Equipment}

\subsubsection{Air Wrenches}

Air wrenches used to remove the process tube caps have been slow and underpowered during previous outages. This was thought caused by inadequate oil supply to the compressed air. This oiling system has been improved, apparently eliminating the problem; however, further observations of these wrenches may reveal additional problems.

\subsubsection{Breaker Bars}

The breaker bars are used on the charge-discharge elevators to loosen the three process tube cap seal bolts. This breaker consists of a socket welded to a 24-inch steel bar. Review of the video tape of charge-discharge reveals that these bars are awkward to handle and time-consuming to use.

The operator must rotate the bar to fit the socket onto the bolt head. Then he rotates the bar through perhaps $60^{\circ}$, removes the socket, and replaces it on the bolt in the original position. This is repeated until the bolt is loose enough to turn by hand. This operation is repeated for each of the three bolts on the cap.

\subsubsection{Process Tube Cap-Installer}

Because the water pressure and volume on the front face are low, the process tube cap-installer is seldom used. However, to speed the work, the cap installer should always be used. The cap installer is identical to the installers used on the rear face where the water pressure and volume is very high. Some efficiencies in size and weight for the cap installers used on the front face would speed this work and should be planned into a redesign of this tool. The current cap installers are awkward to use because the controls are not 
located where the operator can easily reach them. The controls should be at the operator's finger tips when he is supporting a portion of the weight of the machine and pressing it forward on the process tube.

It should be noted here that a design change to the rear face tip-off would place a flapper valve over the process tube. This change is being considered to reduce the quantity of demineralized water consumed during chargedischarge. However, this may increase the water pressure and volume on the front face. This trade-off must be weighed before this change is implemented.

\subsubsection{Radiation Shielding}

One step toward reducing personnel radiation exposure would be to decontaminate areas where radiation is high. A second approach where decontamination is not practical would be to provide temporary or permanent shielding for workers. The front and rear elevators are likely locations for shielding because decontamination will not sufficiently reduce radiation levels. In other areas, such as the basin work areas, decontamination should be considered before procedures for shielding are implemented.

Personnel shielding on the C\&D elevators and elsewhere is necessary to obtain increased charge-discharge rates. Two basic concepts are under consideration for this purpose. The first is to create a house of Lexan plastic that can be filled with water; the second is to create that house of steel-reinforced lead sheets. Both concepts must be removed from the elevators during reactor operation. The plastic house would have walls 2 feet thick; the lead house walls would be 2 inches thick. The plastic house would be easy to move on and off the elevators but would take considerable time to fill and drain. Considering the trade-offs, if there is a place where a house can be readily off-loaded from the elevators and stored during reactor operation, the leadreinforced house has the advantage of being more space- and time-efficient than the plastic house. If off-loading capabilities are inadequate for a fabricated shield, then the plastic house concept should be used because it can be formed in building blocks. This shielding must be movable on the 
C-elevator to allow monotubes to pass. Shielding should also be considered in the canning and capping areas, as well as in other possible beneficial locations.

\subsubsection{Demineralized Water Conservation}

The demineralized water available for charge-discharge operations is limited. In past charge-discharge operations, insufficient demineralized water storage and makeup has limited the number of tubes that could be charged during some shifts. It has also slowed down the charging operations to keep pace with the demineralized water makeup. Increasing charge rates will put additional load on the demineralized water system, placing it on the critical path. Either the capacity of the demineralized water system must be increased or the consumption rate must be reduced. Efforts are underway to place flow restricters on the rear face tip-offs to reduce water loss. Removing fewer caps at a setup on front and rear face can also reduce the consumption rate. This may be realized by using robotics on the C\&D elevators. This problem must be resolved before 500-tube discharges can be implemented.

\subsubsection{D-Elevator Equipment}

Past problems with the tip-off led to a careful look at the mechanisms involved in the current design. Specifically, the mechanism to lock it on the process tube can be improperly set. When this occurs, the position of the locking mechanism can block the fuel from being discharged. When this happens, an operator must take a long pole inserted above the rear face and dislodge the tip-off. In at least a few cases, when the tip-off came off, the fuel discharged, implying that the tip-off was the problem.

That same mechanism has demonstrated some resistance to quick tip-off insertion and release. There are indications that the fuel element space tabs gall the surface of the tip-offs, and that the activity level of the tip-off is higher than desirable, contributing to personnel radiation exposure.

\subsection{FAST CART SYSTEM}

The fuel is carefully inspected, first at the 300 Area and again before it is loaded into the monotubes. A few defective fuel elements are assumed to slip past these inspections. However, estimates of damaged fuel in canisters 
ranged from 10 to 12 percent. Between loading into the monotubes and loading into the canisters, the fuel is subjected to the drop from the process tube onto the trampoline, a fast slide from the trampoline, followed by a severe impact with the steel fast cart and some subsequent direct impacts by the later arrival of fuel into the fast cart. When the fast cart is overturned, this fuel then falls in a semi-controlled fashion into the baskets. The baskets are subsequently dumped onto the separation table for hand-loading onto the canisters. Somewhere within this process the majority of the fuel damage occurs.

This damaged fuel is the primary reason for the use of the canisters. If fuel damage could be eliminated completely, there would be no need for canning. Further, if the damaged fuel could be identified and separated, all the undamaged fuel could be stored without sealed canisters. The cost in time, materials, and radiation exposure required to cope with the damaged fuel puts this on the critical path for productivity improvements.

The fast cart system, in conjunction with the trampoline, causes most of the fuel damage. Assuming that the new trampoline adequately decelerates the fuel and that the decelerated fuel is not struck by the following fuel element while on the trampoline, then the major contributor to fuel damage will be the fast cart system. This damage occurs on both ends of the system, as the fuel drops into the carts and as the cart is dumped into the baskets.

The fast cart system is the only working solution to the irradiated fuel handiing in the immediate future (2 years or more). No instant improvements will eliminate the problems of the fast cart system. It must be properly maintained to continue adequate performance. In working condition, it is adequate to handle discharges to 500 tubes.

\subsection{N-BASIN OPERATIONS}

The charge-discharge basin operations are currently conoucted in approximately the following manner. Three rows of empty baskets are placed in the north basin. The north basin bridge crane operator moves three baskets, one at a time, to the southwest corner of the north basin. The south bridge crane 
operator picks up these baskets, one at a time, and delivers them to the dump chute. The fast cart dumps fuel into these baskets; the south bridge crane operator moves them back to the northwest corner of the south basin. The north bridge crane operator returns them to their row position in the north basin and returns empty baskets to the southwest corner of the north basin. We have been unable to determine any valid reason for this labor-intensive operation. All baskets could be retained in the south basin even for 330 -tube discharges. Discharges of 500 tubes will require some use of the north basin.

During reactor operating periods, the baskets are moved from the north basin to the extreme east end of the $\mathrm{N}$-Basin where the fuel is manually placed into the canisters. The canisters without caps are then moved to either the south basin cubicles or back to the north basin cubicles, depending on the fuel enrichment level. The 0.95 material is placed in the south basin and takes approximately 70 cubicles. The high enrichment fuel is stored in the north basin and requires approximately 100 cubicles. The east half of the north basin contains old fuel in Mark 0 canisters; this fuel will not likely be recanned and shipped until sometime in 1984.

\subsubsection{Storage Delays}

The fuel is currently left in the baskets for 18 days before canning. It then remains in the cubicles uncapped for 150 days, after which it is moved to the southwest corner of the south basin for capping and shipping.

The 150-day wait before capping and shipping probably cannot be reduced to zero. Therefore, any reduction represents only a better utilization of cubicle space. This has the potential of providing acditional cushion for fuel storage if shipping is interrupted for some extended period. It is not considered a high priority item in increased fuel discharges.

\subsubsection{MK I Canister Design}

The MK I canister is an example of excellent engineering design. However, it is expensive and extremely labor-intensive to install the caps and assure positive seals. The MK II design has reduced many of these problems. However, 
it requires a significant engineering effort to remotely remove the caps at PUREX. To solve these problems, a new cap design is needed that would meet the functional requirements, be much faster to install and less expensive to make, and be easily removed at PUREX. If a further test of three capped canisters stored in a cubicle with new fuel demonstrates acceptable cooling, the caps could be installed during the canning operation. This would reduce the effort required prior to shipping to place the nitrogen cover gas on the canisters. It would also allow identification of canisters containing damaged fuel.

\subsubsection{Casks and Well Cars}

Casks and well cars are expected to be provided in adequate quantities to handle increased shipping requirements of the larger discharges. These items must also provide shipping of fuel from K-Basin to PUREX and N-Basin for recanning. The existing system is adequate for the required service; hence, no design recommendations are provided in this report. Individuals responsible for recanning and shipping of stored fuel are expected to procure necessary casks and well cars to meet their requirements.

\subsubsection{Recanning Operations}

Impacts of recanning operations on $\mathrm{N}$-Basin work will have to be considered in the near term. Elimination of the basket system would greatly reduce these impacts. Further relocation of various work functions could also lessen these impacts.

\subsection{REMOVAL OF EQUIPMENT FROM N-BASIN}

A quantity of unused equipment is currently stored in N-Basin. Before the recommended changes in basin operations can be fully implemented, this excess equipment must be removed from the basin. Material removal will require preparing one or more design changes.

\subsection{RECANNING OPERATION (KE-BASIN)}

All the fuel in KE-Basin must be recanned before shipping to PUREX for processing. This operation may impact the $\mathrm{N}$-Reactor charge-discharge operations by placing additional personnel radiation exposure loads on the UNC staff 
and requiring additional casks and well cars to ship this fuel. It will also affect the railroad system and scheduling of the movement of cars. These impacts must be evaluated and plans worked out before the recanning operation gets underway in 1984-1985.

\subsection{COMMUNICATIONS}

Al1 work on the charge machine, the C\&D elevators, and the fast cart systems must be coordinated to achieve charge-discharge. A system of interlocks between systems in the various work areas ensures that everything is in its proper place before irradiated fuel is pushed out of the reactor. This requires a complex communication system throughout these areas. Upgrading of this system is being managed and funded by the Restoration Program and will not be addressed in this study. However, during the next 3 to 5 years, this system will require continued attention to assure that it remains fully functional and does not contribute to outage extensions. 


\subsection{SPECIFIC TASK RECOMMENDATIONS}

Recommended tasks to improve the critical path systems and features are described in this section.

\subsection{UNIRRADIATED FUEL STORAGE}

Short-term measures to accommodate one-third reactor charge-discharge should include more efficient use of Room 181 and the possibility of moving some special fuel to 300 Area for storage. This will require closer cooperation between personnel responsible for 300 Area fuel fabrication and $\mathrm{N}$-Reactor requirements so that fuel can be shipped on shorter notice.

In the longer term, the 500-tube charge-discharge operation would require storing 140 loaded monotubes in addition to the required additional boxed fuel storage. The monotube problem will be discussed in Section 3.2. The most expedient solution for boxed fuel storage for 500-tube charge-discharge is to establish a site at 300 Area for fuel storage for the second half of a 500-tube charge, then order that segment of the fuel shipped on the appropriate day in the monotube loading operation. This recommendation recognizes that the longer reactor operating period allows more flexibility in monotube loading and that shipping from 300 Area can be accomplished in 5 working days.

We recommend that controlled shipments of fuel from 300 Area be combined with better use of available fuel storage space at $\mathrm{N}$-Reactor to provide the necessary quantities of fuel for 333- and 500-tube charge-discharge operations. For 333-tube loading, the space at $105-\mathrm{N}$ is curently sufficient and procedures are adequate. For 500-tube charge-discharge, the procedures would be modified to provide spaced shipments of fuel by charging all available tubes in Room 29 during the normal operating period. When this operation is complete, the balance of the required fuel would be shipped from 300 Area and stored in the fuel storage room. This fuel would be charged into the special monotubes and stored in Room 181 in appropriate racks as described in Section 3.2. This recommendation requires redesigning the monotube loader, but allows use of the existing charge machine as well as minimal redesign of the replacement charge machine. 
An alternative approach woula be to divide the charging operation by reloading enough monotubes to complete the 500-tube charge-discharge operation. This coula be accomplished with the charge machine and existing monotube loader or with the redesigned monotube loader. However, it would increase the outage time required and, therefore, is not as productive as the primary recommended approach.

\subsection{MONOTUBE SYSTEM}

The enrichment counter should be replaced with a state-of-the-art system. It is not yet clear that the enrichment counter is required in the current or future planned fuel campaigns. The enrichment counter could be relocated at 300 Area fuels loading and each box of fuel would be certified before shipment to $N$-Reactor. Alternatively, procedures could be established to ensure that monotubes were charged with the proper fuel in the correct order. In any event, the need and application of the enrichment counter shoula be evaluated before a new system is designed and purchased. This system, if required, should be designed and packaged so that it can be removed and reinstalled on a replacement monotube loading system at a future date.

A monotube drying system must be designed, fabricated, and installed as soon as possible. The ultimate solution should be the one that can be implemented in the proper time frame and will generate the least radiation exposure.

An inspection system should be established to identify monotube defects and wear-out. Replacement tubes should be ordered as required to maintain an adequate supply on hand. Design deficiencies should be identified in these inspections so that improvements can be implemented $i r_{1}$ new procurement.

Long-term problem areas relate mainly to end-of-life failures for the mechanisms involved in the sorter and monotube loader.

The monotube problem is the prime obstacle to implementing 500-tube charge-discharge. Room 29 is inadequate for storing sufficient monotubes. A potential solution to this problem is to interrupt the charge-discharge operation with an intervening monotube loading operation. This could be accomplished with the existing system, but would extend the outage and force 
labor-intensive efforts in the middle of an already busy outage. However, this solution to the monotube storage problem may be acceptable as an interim measure.

The most promising solution is to fabricate 28 special monotube assemblies. Each assembly would consist of five parallel monotubes approximately 30 feet long. Each individual tube in the assembly would hold one monotube charge of fuel only. These assemblies would be stored on wall racks in Room 181, as shown in $F$ igure $1, F$ and $G$. Referring to the figure, the normal charging of monotubes in Room 29 would be accomplished by locating the component $D$ at the dashed location $E$. In this configuration, $D$ meshes with the $C$. $D$ contains the fuel sorting, examination, and loading systems while $C$ provides five mating tubes to contact the five empty monotubes on the charge machine at $B$. Spacers and fuel are loaded at $D$ into five tubes at once. The five parallel spacers or fuel elements are mechanically pushed into the five tubes at $C$. The next set of five spacers or fuel elements is positioned on $D$ and pushed into the tubes. On each of the five tubes is a sensor to measure the length of each element charged. This information is stored in a minicomputer to provide a real-time record of each fuel element length, as well as the total length of each charge. The information is related to the monotube being charged and its location in storage. A permanent record is prepared by dump printing as required. When the last spacer is charged into the $D$ segment, a second mechanical system clears the $D$ segment by pushing the fuel column into the $C$ segment. The mechanical system on the $C$ segment then pushes the entire charge into the monotubes. The $C$ segment then withdraws to clear the monotubes. The charge machine stores the five loaded monotubes and returns with five empty monotubes. This process is continued until all 360 monotubes in Room 29 are loaded and stored.

Referring to Figure 1 again, the special monotube assemblies in Room 181 are loaded in the following manner. The sorting, examination, and loading section is moved to location $D$ as shown in Figure 1 . Special monotube assemblies are moved from their storage position to position $\mathrm{H}$, where they are loaded with fuel only, capped, and replaced in their storage locations. During the outage, some or all of the 360 loaded monotubes in Room 29 are charged into 
RM 29

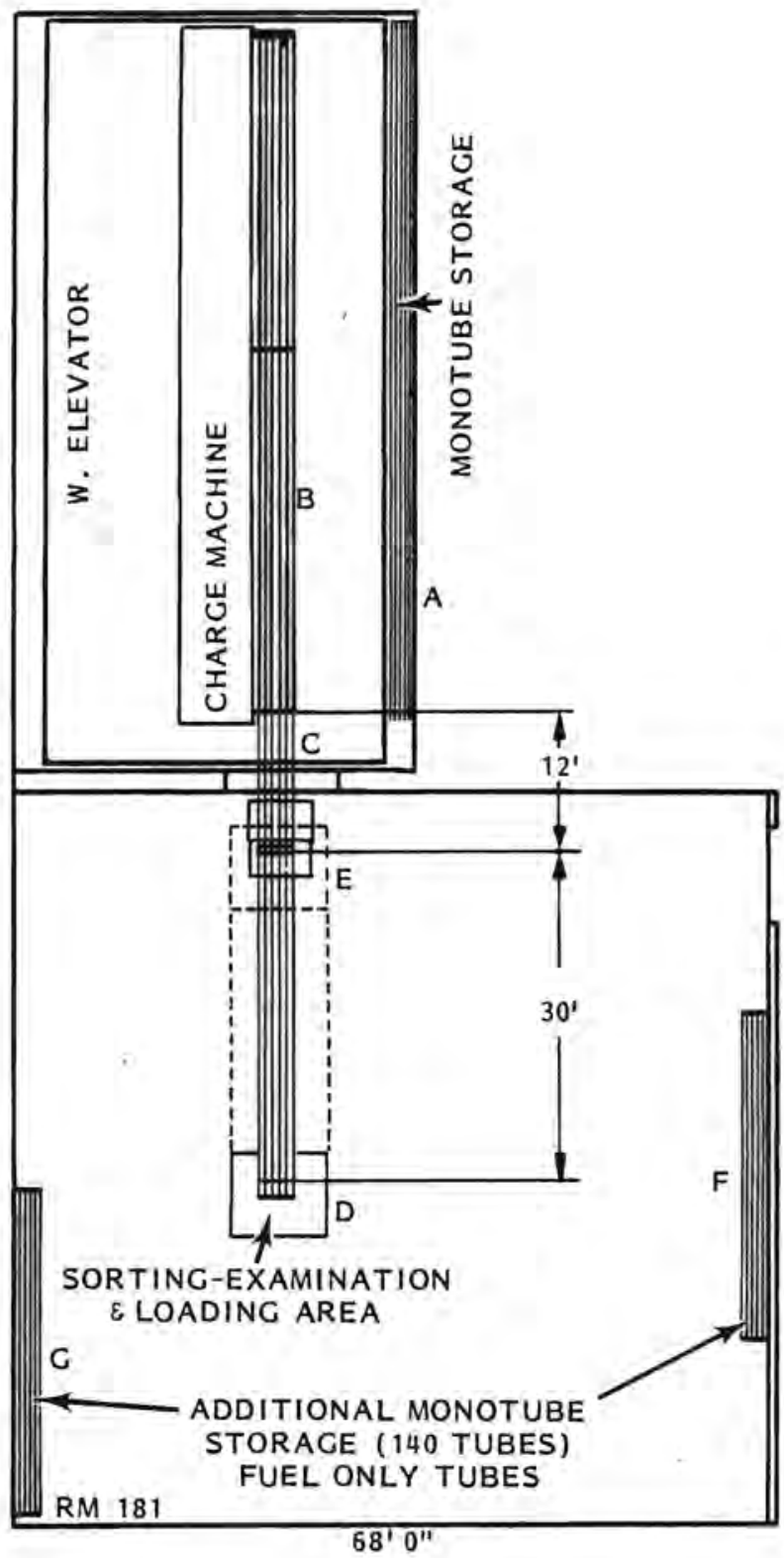

FIGURE 1. Conceptual Design for Monotube Loading and Additional Loaded Monotube Storage to Obtain 500-Tube Charge-Discharge

the reactor. Then the special monotube assemblies are removed from storage and placed at position $H$ in Figure 1 . The downstream spacers are loaded into section $C$. With the special assembly in place, the upstream spacers are loaded into the special assemblies at $D$ and five complete fuel columns are pushed into 
empty monotubes on the charge machine. These loadea monotubes are replaced on their racks until all the special monotubes are emptied. Then the remainder of the charge-discharge operation is completed, ending the monotube loading operation cycle.

Implementing these fuel flow path improvements would result in obtaining 500-tube charge-discharge operations. This recommendation requires a minor modification to the charge machine, redesign of the monotube loader, and design and purchase of the special monotubes and their storage racks. It does not alter the radiation zoning status of any existing rooms. The redesigned monotube loader would be capable of reducing the time required to load fuel into monotubes on the charge machine. The concept presented here represents what we consider to be the best approach to achieving 500-tube charge-discharges.

\subsection{CHARGE MACHINE REPLACEMENT}

Replacement of the charge machine could be accomplished in approximately 2 years from initiation of this task. The mechanical and hydraulic component designs should be upgraded to incorporate improvements as outlined in the following subsections.

The control system upgrade to state-of-the-art electronics is already underway as part of the Restoration Program. These changes should be incorporated into the replacement charging machine and not into the existing unit. This conclusion is based on the fact that several months of downtime would be necessary to solve interlock and control problems if the entire control system were removed from the charge machine and a new one installed. This downtime is unacceptable to the only operating charge machine.

On the other hand, a replacement charge machine could be assembled and tested, either in 1890 or in the 314 Building where the existing charge machine was mocked up. The control system, as well as the rest of the functions, could be completely checked out. Then, on a prearranged day, the existing charge machine could be jacked up, taken out, and replaced by the new, fully-tested machine on the $W$-Elevator. This new charge machine would have all of the modifications required to accommodate 500-tube discharges in the most efficient manner. 
Onsite modification of the existing charge machine seems impractical because of time requirements potentially impacting reactor outage. However, if this effort were undertaken, design recommendations are offered, based on three assemptions:

- continued operator presence

- use of current monotube configuration

- monotube wall racks identical to current configuration.

\subsubsection{Drive Rollers}

The basic drive roller design is sound. Changes recommended to eliminate slippage include:

- replace drive rollers opposed by stationary idlers with a double roller "pinching" arrangement capable of vertically floating to eliminate dependence on support roller alignment and monotube straightness and minimize effects of roller wear

- investigate improved roller rubber or polymeric coatings

- consider providing a small degree of yaw control to minimize monotube to charge hole interference.

\subsubsection{Transfer Arm System}

Modifications to allow loading of monotubes while on the transfer arms will be required if the proposed special monotube system is implemented.

\subsubsection{Vertical Lift}

This system is of sound design and appears to need no modification.

\subsubsection{Cross Travel Drive System}

The speed with which the charging machine is able to traverse the elevator is not a major impediment to the charge-discharge process. Horizontal tube alignment difficulties created by overshoot appear to stem from drive system inertia, cumulative backlash, and insufficient control articulation. Several approaches are possible: 
- Design and longitudinally stiffen main frame to eliminate the necessity of eight drive pinions. This will simultaneously reduce rotating inertia and cumulative back lash due to many driven members with a single drive source. Widening the platform and using box frame members does not appear to create a space problem.

- Incorporate an inching mechanism in the hydraulic drive motor.

- Provide self-energizing brakes as close to drive trucks as possible.

- Replace current gear reduction systems with worm gear or other self-locking mechanisms.

\subsubsection{Long-Term Resolution of the W-Elevator Failures}

The W-Elevator failures should be greatly reduced by the efforts of the restoration program. No recommendations are provided here.

\subsubsection{Fuel Charging System}

Final monotube-to-reactor nozzle seal is accomplished by one or all of three hydraulic cylinders raising and engaging the cone-shaped monotube nozzle, subsequently pushing the monotube the last several inches and utilizing the cylinder's force to effect a seal on either end. A teflon coating is employed to aid sealing at the reactor nozzle/monotube interface. The rear monotube nozzle, however, is metal-to-metal contact. Leakage from this connection causes wetting of both electrical and hydraulic components.

\subsection{ELEVATOR TOOLING REDESIGN}

The hand tools utilized on C\&D elevators have been obtained off-the-shelf or have been fabricated in the UNC shop. They have never been optimized for fast, efficient operations. We recommend that each hand tool in use be redesigned as required to speed the charge-discharge work.

\subsubsection{Air Wrenches}

The air wrenches now used to remove process tube caps are adequate to perform their required task when they are in good condition and when all other systems are optimal. We recommend that the air wrench market be surveyed for 
a better tool, one with sufficient power to easily overcome resistant caps and to quickly remove the cap once it is cracked loose. In addition, the driving head should be configured with an automatic gripping and release design so that the caps do not bond themselves to the socket. Although not a high priority item, this will speed the work on the elevators, thereby contributing to overall efficiency.

\subsubsection{Breaker Bars}

New breaker bars should be fabricated as shown in Figure 2. This conceptual design consists of a socket attached to a ratchet. On the back of the ratchet a tee handle is located. The breaker bar extends from the ratchet and is made with a sliding extension for added torque when required. The operator grasps the tee handle with one hand and the 15-inch bar with the other hand. He places the socket on the bolt head by rotating the tee handle until the socket matches the bolt. He then uses the breaker bar to loosen the bolt with

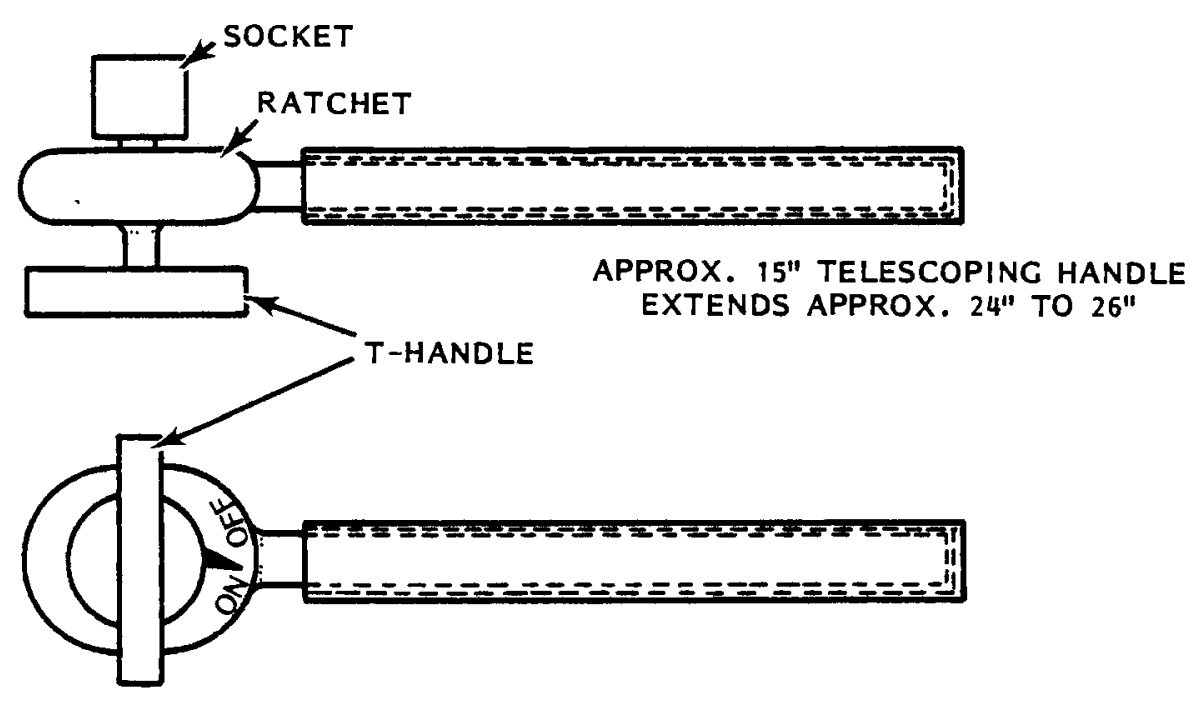

FIGURE 2. Breaker Bar Redesign 
an up and down motion until it is loose enough to turn with the tee handle. He then turns it with the tee handle to the aesired position and moves to the next bolt.

\subsubsection{Torque Wrenches}

The torque wrenches in use on the front and rear elevators are standard off-the-shelf click-type wrenches. A reduction in radiation exposure and time could be realized by designing a torque wrench head with a speed wrench handle. A further reduction could be realized with a two-speed air wrench. The first high speed tightens the three bolts evenly. Then the wrench is switched to the low speed-high torque setting and each bolt is torqued with the air wrench.

\subsubsection{Process Tube Caps ana Removal/Installation Tools}

In the near term, speeding work on the front and rear elevators must revolve around existing major systems. In the long term, major system improvements should be implemented. We conclude that redesigning the existing process tube caps would save time, lower radiation exposure, and reduce the incidence of skin contamination. To achieve these improvements, the three sealing bolts must be eliminated and replaced with a single bolt. A process tube caps designed to accomplish the closure and the sealing with a single threaded connection would be ideal. Figures 3 and 4 show two conceptual designs that address these goals. These are not to be considered final; only preliminary calculations have been performed on the thread designs. Obtaining process tube caps such as these will require torquing the final process tube sealing surface with a machine because the torque required to obtain a seal is higher than those normally applied with manually-operated tools.

The redesign is feasible if one assumes that the torquing operation is done with a tool instead of by hand. With off-the-shelf torquing tools, torques of 300 to $400 \mathrm{ft}-1 \mathrm{~b}$ are readily available. Two process tube cap redesigns merit consideration. In the first concept, the existing female thread on the cap would be screwed onto the process tube and locked in place. A second female thread, larger in diameter than the processing tube, would be cut into the end of the process tube cap. The sealing insert would be pivoted on 

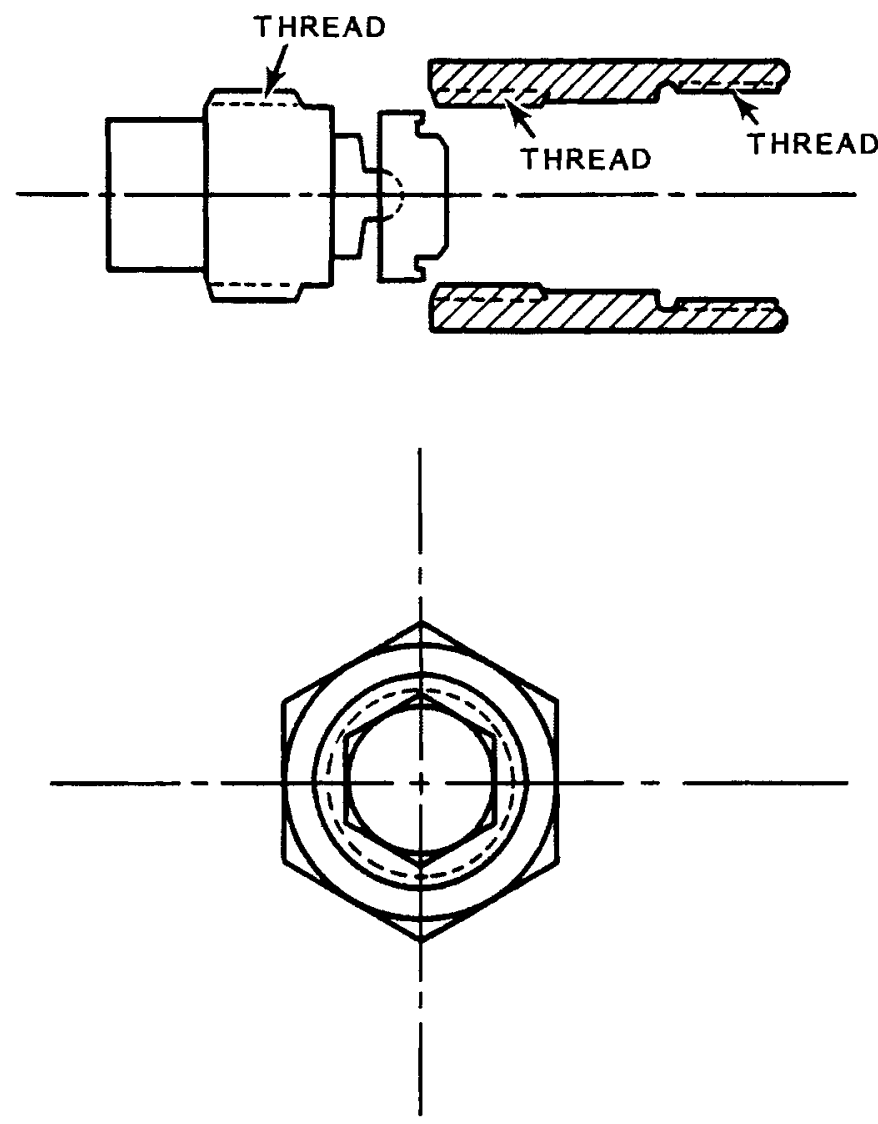

FIGURE 3. Conceptual Design for Improved Process Tube Cap 

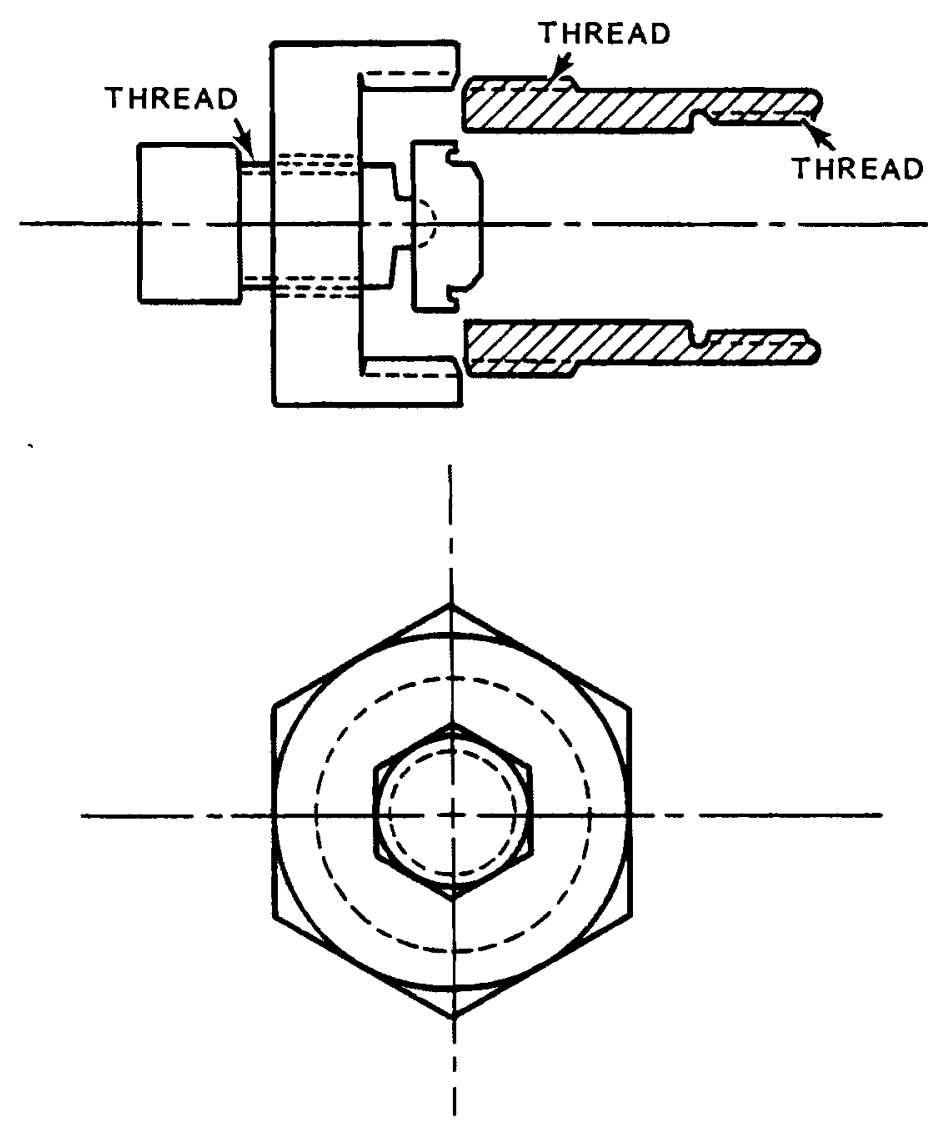

FIGURE 4. Conceptual Design for Improved Process Tube Cap

the inside of the mating plug. This plug would have the appropriate selfguiding threads to meet the operating requirements of the seal surface at a torque of 200 to $300 \mathrm{ft}-1 \mathrm{~b}$. The outside of this cap would have a 2 -inch hex head, allowing use of a single socket on the power tools to break the tube seal and remove the cap.

The process tube cap installer should be redesigned. The C-Elevator model could be reduced in size but not in length. Both the $C-$ and D-Elevator units should have better elevation controls. The functional controls should be on pistol grips as part of the handholds for positioning and pressing the tool onto the process tube. This tool should also do the torquing of the seal bolts as a second operation. Effort is underway at HEDL to design a tool to 
locate and tighten the three bolts on the current process tube cap. This tool will be necessarily complex and more prone to failures than if the process tube seal could be achieved with a single bolt.

If the process tube caps were redesigned as suggested in Figures 3 and 4 , the cap installer could be further simplified. The cap design shown in Figure 3 could be installed with a single socket tool that develops the necessary torque to seal the process tube. This installer design would significantly hasten the C\&D Elevator work. Its implementation would require adding thread protection on the tip-off and on the monotube guide attachment.

The second cap design concept simply replaces the three sealing bolts with a single bolt in the center of the cap. Again the torquing requirements are higher than those usually considered for hand-applied bolts. However, the work on the C\&D elevators is best and most quickly done with power tools. This concept requires two sockets on the air wrenches to first break the sealing bolt and then remove the cap with a larger socket. This could be best accomplished with a double-ended socket on the air wrench or with a spring-loaded socket for the seal bolt inside the larger socket for removing the cap. The cap installer would require the same two sockets, using the larger socket first to install the cap and then retracting that socket to drive the sealing bolt head and apply the torque. Again, the controls on these tools would be on the handles so that the operator could perform all functions with a minimum of movement.

\subsubsection{Tip-Off Development}

We recommend that a study underway at HEDL include any potential benefit that might occur by virtue of redesigning the tip-off to intentionally impart rotation to the fuel elements. Placing rotation on the fuel element will greatly increase its deceleration as it enters the water and increase the impact area on the trampoline, thus reducing the forces impacted to the fuel element and the trampoline. This would tend to increase the useful life of the trampoline while reducing fuel damage. 


\subsubsection{C\&D Elevator Robotics}

This is the only development area listed in the schedule that cannot be completed in time to meet the goal of 500-tube charge-discharge by the start of FY85. Therefore, we recommend that the previously discussed tooling redesigns to improve C\&D elevator operations have priority over this concept.

The major personnel radiation exposures during charge-discharge operations result from three to five men working on each elevator for the entire charging operation. The use of robotics on these elevators would decrease the personnel required to one man per elevator, and that man could remain in a low radiation area much of the time. In addition, the work could be accomplished faster and with reduced requirements for demineralized water.

On the C-Elevator the machine would consist of a base mounted on geared tracks in the elevator floor. The base would be positioned by stepper motors for both horizontal travel along the elevator floor and vertical travel to access the one or more rows of process tubes. This machine would be capable of locating a specific process tube cap and removing the cap, removing the first spacer, then installing the monotube adapters. The adapter coula be an integral part of the machine, in which case the machine would remain while the monotube and the tube would be charged. When the charging was completed, the machine would then reinsert the spacer, replace the cap and then proceed to the next tube. A second approach would be to allow the machine to install the monotube adapter and go on to the next tube, returning after the tube is charged to remove the adapter and replace the cap. A third approach would be to hone two machines on the same track, one to remove and replace caps and the second to place and hold the monotube adapter.

On the D-Elevator, the machine or portion of the machine to remove the caps would be identical to the C-Elevator unit. The balance of the system would be capable of placing the tip-off on the tube and then removing it after discharge. With some modifications to the elevator, it could be viable to allow the tip-off to be an integral part of the machine. This would allow the elevator to remain in the working position during discharge operations, which woula save a great deal of time and allow only one process tube cap to be removed at any time. This would virtually eliminate the demineralized water problem from the critical path. 
Implementation of these robotic devices on the C\&D elevators also removes the C\&D elevator work from the critical path for 500-tube discharges.

This robotic concept also allows the consideration of separating discharge operations from charging operations. This would require additional design parameters on the machine on the C-Elevator. Although the benefits of this effort are not clear, it should be given careful study before the system design is initiated.

The robotic concept permits consideration of eliminating or drastically reducing the use of spacers. This could be accomplished by removing the 4.5 feet of spacers from the process tube with the robot on the D-Elevator. After discharge the robot removes a feed-through spacer that was in the monotube and reinserts into the process tube the same spacer it removed before discharge. The feed-through spacer is then recycled into the next chargedischarge after mild decontamination. The procedure on the C-Elevator would be the same except that the spacers total 7.5 feet in length and the fuel seating spacers would remain with the monotube. Obviously, reusing the same spacers would result in ever-increasing levels of radioactivity in these spacers. On some programmed basis the spacers would be dumped into the basin and new spacers would be inserted into the process tubes. This process could result in an 80 to $90 \%$ reduction in the number of spacers consumed per year and further speed the monotube loading operation. In addition, elimination of the spacers in discharged fuel would result in an immediate increase in the number of tubes of fuel permitted in the carts and baskets. This would result in a $25 \%$ reduction in the number of baskets required and in operator time to separate the spacers from the fuel. It would also reduce the time and expense of chopping the spacers up and sending them to radioactive burial.

\subsection{FAST CART SYSTEM}

Continued preventive maintenance and upgrading of the fast cart system is essential to existing charge-discharge fuel quantities. These tasks will be even more important when the quantities of fuel, discharged are increased.

In the longer term, the fast cart system should be replaced. The criteria for the replacement device or system include the following: 
- it must eliminate fuel damage

- it must be capable of moving fuel from the discharge area to the basin at speeds matching or exceeding the 10 tube/hr discharge rate

- it must be capable of separating broken fuel and spacers

- it must be compatible with direct fuel canning, but it must also be compatible with the current basket system

- it should present fuel for canning such that the identity of the fuel going into each canister can be tracked

- it must be of simple construction, highly reliable and easily maintained and repaired.

A conceptual design believed to meet these requirements will now be described.

Figure 5 shows a conceptual design of a conveyor system that is modular in design and utilizes the existing fast cart track system for installation ana removal. The system consists of seven identical conveyor segments pinned together much like boxcars are connected. The chain conveyor is a single continuous loop powered from a motor drive in the basin area. The top of each module unit consists of a bolt-on segment that provides the specific function for that module. For example, Section A-A of Figure 5 is the fuel collection area in the rear face. The fuel drops off the trampoline and onto the conveyor on the 20-foot long module. The fuel is decelerated and turned to avoid collisions with other fuel elements. Then the elements drop onto the chain and $c$ an be stacked three elements high. They can be cocked or handled in a random fashion. At Section B-B, the upper portion of the mocule is designed to separate the stacked or cocked elements. This is accomplished by the beneficial use of friction and gravity. Section $C-C$ shows how the elements are separated and conveyed into the basin. Section D-D depicts the off-loading areas. Again, the top of the module is modified to allow the elements to be rolled off the chain with a water jet from a nozzle or a mechanical arm. The off-load areas are set up to separate spacer and broken fuel elements so that more fuel can be placed in each basket. The off-loading areas can use the existing basket system or can easily be converted to direct canning if that becomes a viable option. 

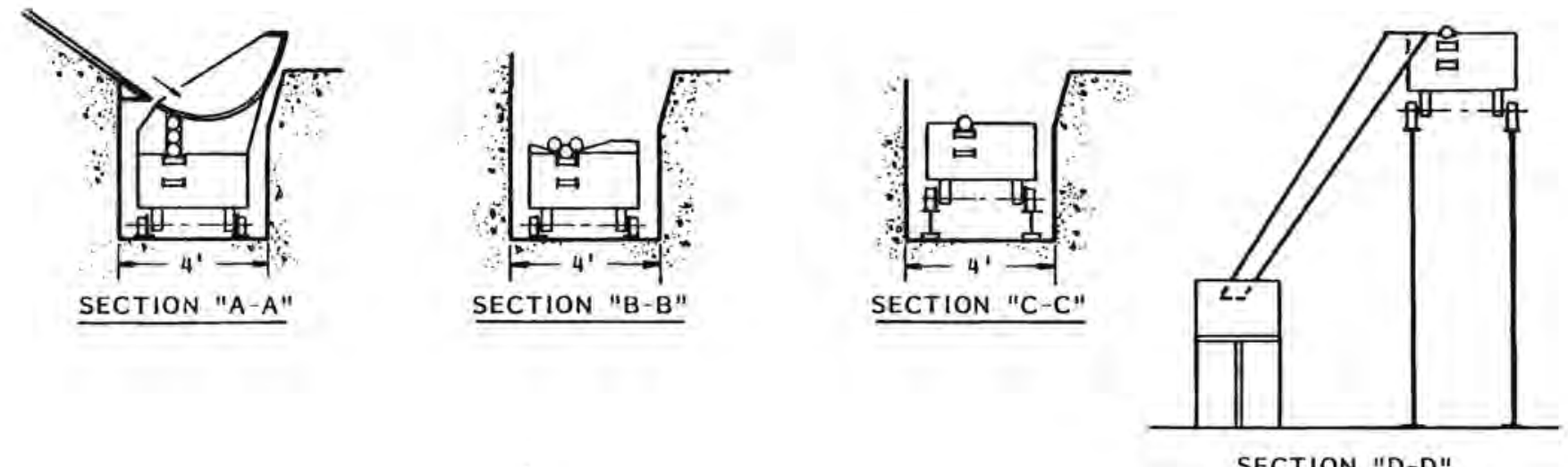

$\omega$

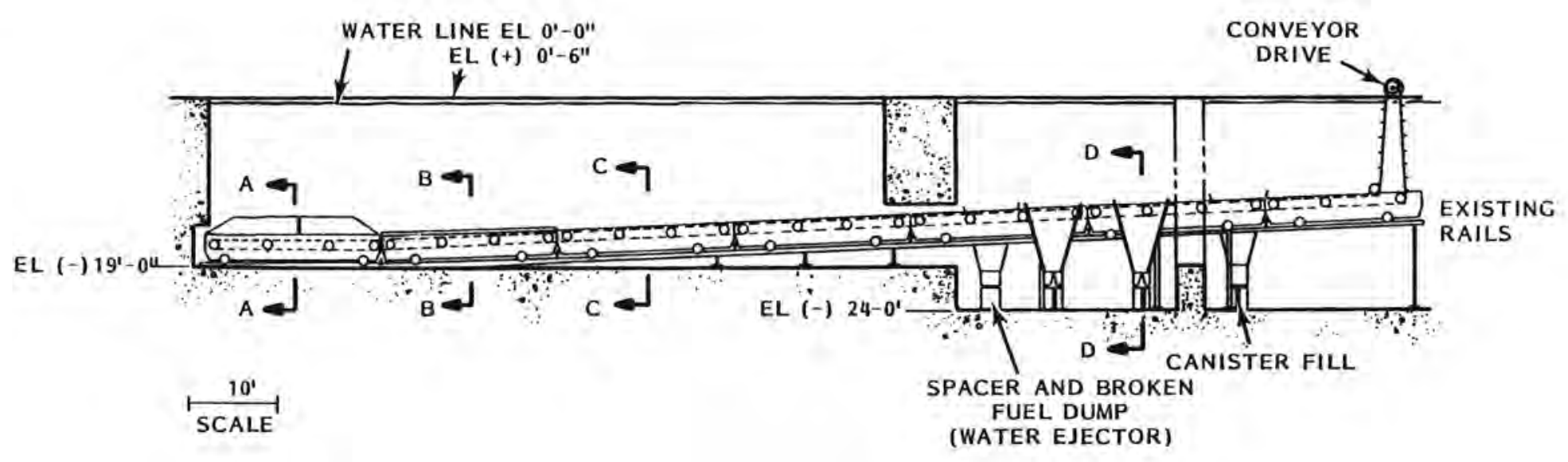

FIGURE 5. Conceptual Design for an Irradiated Fuel Conveyor 
The chain would be designed to wear out before it breaks under load. The worn-out condition would be detected by elongation measurements in the tensioning system. In the event of failure, or to initially install or replace the chain, the modular system is placed on the tracks in the basin and each segment is pinned to the next section. As assembly proceeds, the system extends toward the rear face area. The entire intact system can be pulled out into the basin for repairs or maintenance. The normal wear-out areas are primarily on the bolt-on added top segments of each module and can be replaced as required.

If adopted, this system would markedly reduce fuel damage and potentially reduce or eliminate the basket system.

\subsection{BASIN VENTILATION IMPROVEMENT}

During charge-discharge operations, the basin area sometimes becomes contaminated with excess airborne radioactive gases. This trips the radiation alarms and operations must be stopped until the airborne radiation is vented. Some temporary solutions to this problem have been implemented in past chargedischarge operations, but final solutions woula require a design change. This design change should provide sufficient ventilation in the basin and rear face areas to maintain the airborne radiation levels well below alarm levels during charge-discharge operations.

\subsection{BASIN WORK REORGANIZATION}

Figures 6 and 7 show the basins and cubicles are currently used. Figures 8 and 9 show revised plans for basket utilization for 333-tube discharges and for 500-tube discharges. If the conveyor system is included in the planning, each basket can be loaded with another tube of fuel because the spacers have been removed. This reduces the number of baskets required for these charge-discharge batch sizes. Direct canning would eliminate the baskets altogether, significantly reducing the work and radiation exposure in the basin area. 


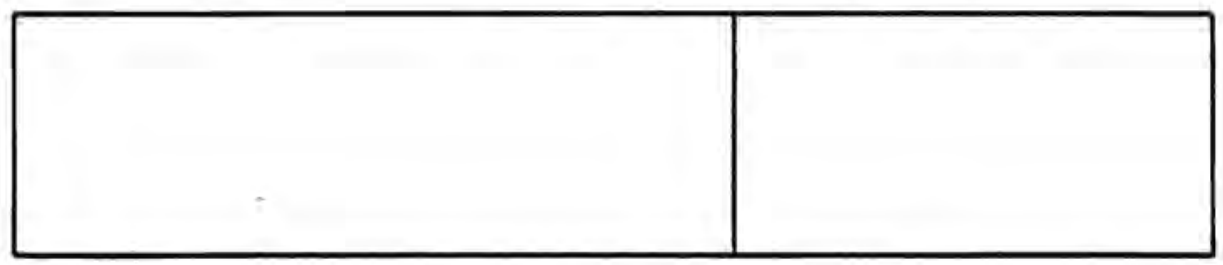

NORTH BASIN

\begin{tabular}{|l|}
\hline 111 \\
\hline 1111 \\
\hline 11111 \\
\hline
\end{tabular}

MAX. 30 BASKETS PER ROW

FIGURE 6. Current Empty and Full Basket Arrangement

SOUTH BASIN

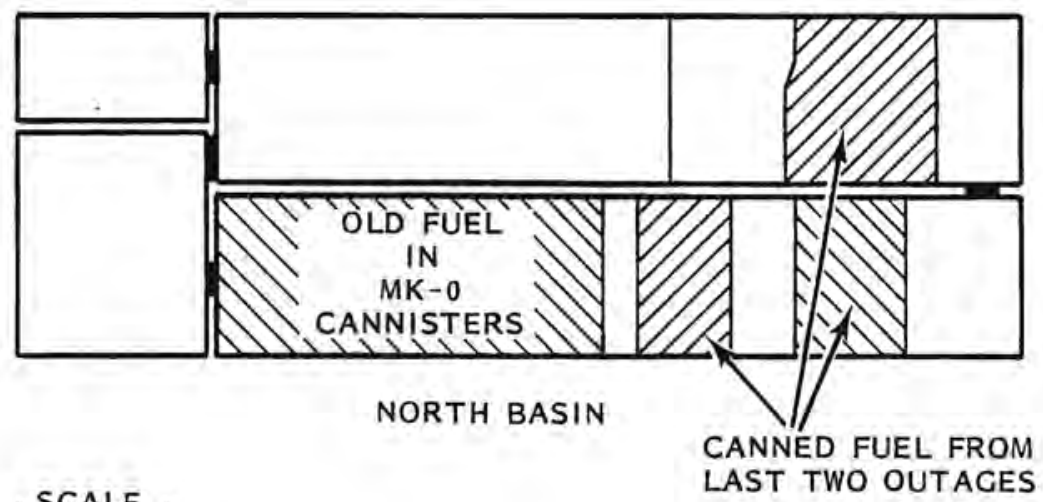

$\frac{\text { SCALE }}{18 \text { FEET }}$

LAST TWO OUTAGES

FIGURE 7. Current Cubicle Utilization Plan 


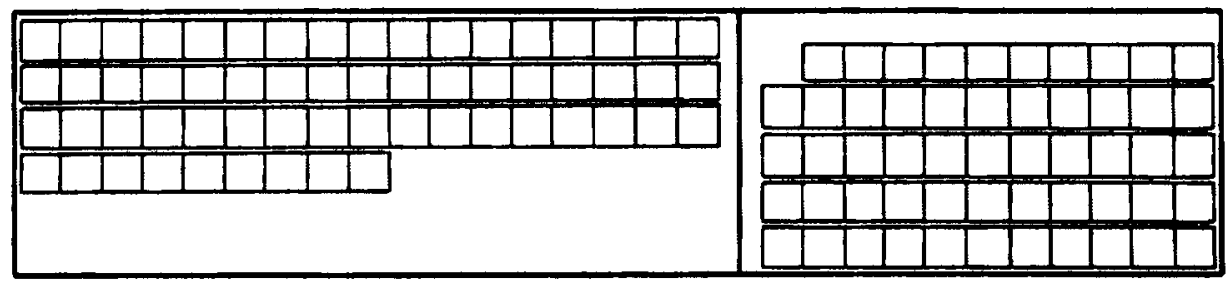

NORTH BASIN

ASSUMES NOMINAL 3 TUBES/BASKET

110 BASKETS REQUIRED

WITH SPACER SEPARATION:

4 TUBES/BASKET

85 BASKETS REQUIRED

FIGURE 8. Proposed Basket Arrangement for 333-Tube Discharge

SOUTH BASIN

60 BASKETS

54 BASKETS

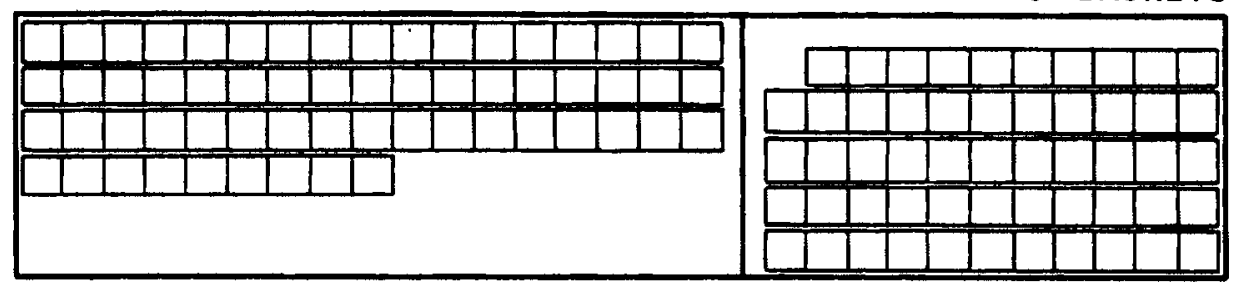

NORTH BASIN

52 BASKETS

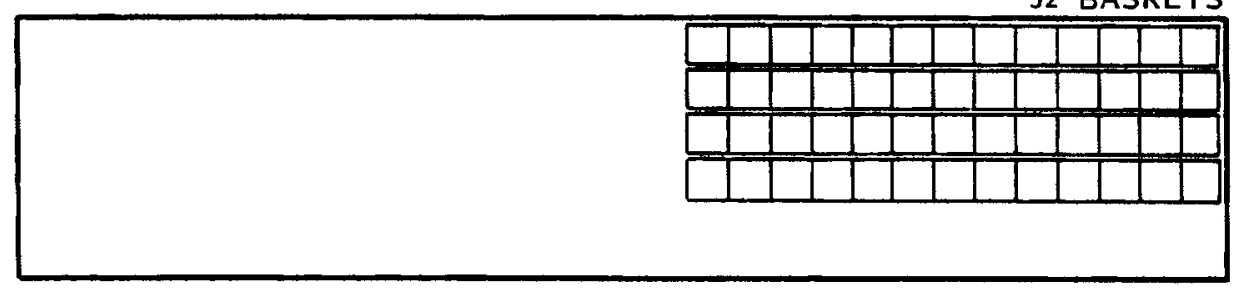

ASSUIMES NOMINAL 3 TUBES/BASKET

166 BASKETS REQUIRED

WITH SPACER SEPARATION:

4 TUBES/BASKET

125 BASKETS REQUIRED

FIGURE 9. Proposed Basket Arrangement for 500-Tube Discharge 


\subsubsection{Basket Utilization Modification}

Basket utilization within the basin should be immediately modified so that the empty baskets are placed in the west end of the south basin. The south bridge crane operator would then move three baskets to the fast cart dump area. When the baskets were filled, he would move them to the southeast wall of the basin and bring new baskets to the dump site. This operation would continue until the southeast end of the basin is filled to three or four rows wide the full length of the portion of the basin without cubicles. Filled baskets would then be placed in the west end of the south basin until discharge was complete.

This process can be extended to 500-tube discharges by using some additional basket storage in the north basin. Separation of the spacers and damaged fuel would reduce the required number of baskets by $25 \%$.

\subsubsection{Canister Redesign}

The existing canister is provided to isolate damaged fuel from the storage basin water, reducing the contamination of the basin water. Eliminating or separating damaged fuel would reduce the need for the canister. If the damaged fuel could be identified while in the canisters, before shipment to K-Basin, alternative procedures could be implemented to reduce the utilization of canisters. This could be accomplished by direct canning with a cap and then measuring the activity of each can before shipping to K-Basin. Further evaluation of the origin of damaged fuel and data gathered from capped canisters could result in reduction or elimination of the use of canisters. We recommend that this topic be pursued as changes are implemented into the fuel flow path.

The canister used now is carefully designed to be sealed and leak-free, but also provides a direct vent for gases to the basin. Therefore, the comr plete leak-free seal is, in effect, circumvented by the vent system. The MK I caps are expensive and time-consuming to install and remove. We propose a redesign of the cap and the canister to provide the same integrity with a cap that is easier to install and remove. Figure 10 is a conceptual design for such a cap. The cap is not sealed to the canister, but rather provides a significant gas cavity under the lid, which is in communication with the cover gas in the canister. The canister water communicates by openings in the pipes 


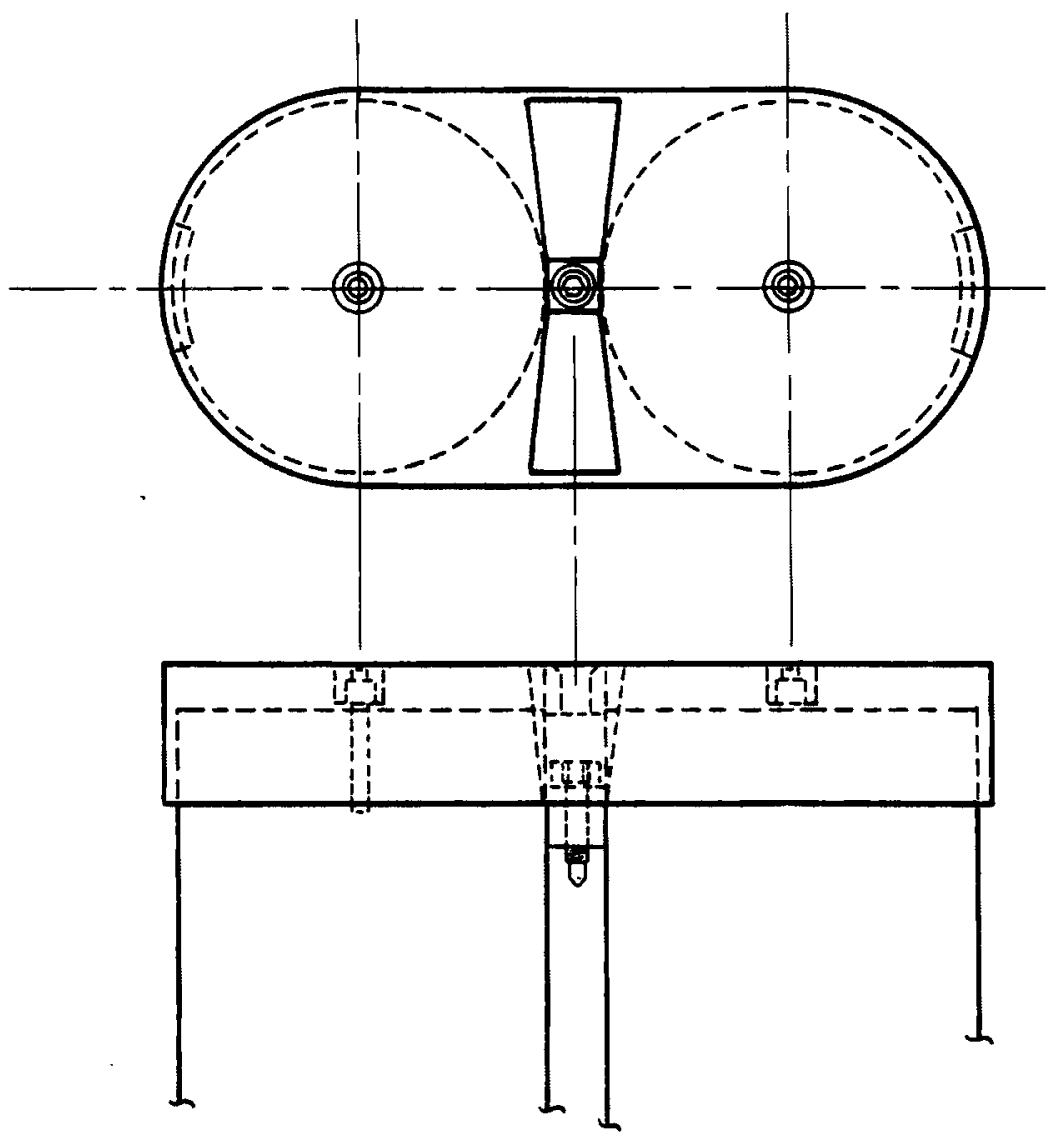

FIGURE 10. Conceptual Canister Redesign

connecting the two cans. The cap is attached to the canister with a single Allen head bolt. This design is compatible with existing hooks on the bridge cranes. The hook is guided into the proper position under the lifting bar by the formed depressions in the lid. The nitrogen gas supply is attached to the right valve and a bleed line is attached to the left valve. As nitrogen is supplied to the canister, the bleed line removes water until the appropriate water level is achieved inside both cans. The bleed 1 ine is then removed and nitrogen gas flow is continued until bubbles begin to emerge from under the 1id. The canister is then ready for long-term storage.

This cap design operates exactly as the current design, but is much faster to install and remove and requires no sealing or leak checking. Any redesign 
of the canister must be compatible with the handling tools currently being used and with the cap removal and canister dump system being designed for PUREX. An early resolution of the benefits versus the technical problems of implementation should provide direction on this recommendation. 


\subsection{CONCLUSIONS}

The fuel flow path presents many technical challenges. Overcoming those challenges can result in improvements in the charge-discharge operations. These improvements permit increases in batch sizes of fuel charged in a given period of time, longer operating periods for the reactor, and reduced numbers of outages per year. However, reductions in personnel radiation exposure must be achieved before any of the other benefits can be realized.

This study concludes that an estimated $31 / 2$-year plan should be adopted to achieve as much productivity improvement as possible while systematically upgrading the charge-discharge equipment, procedures, and personnel proficiency to provide the necessary reduction in radiation exposure. This charge-discharge plan must dovetail the engineering efforts already underway with additional tasks in a manner that maintains the current reactor operating integrity while implementing new equipment and procedures. It must also coordinate the efforts of many components of UNC as well as the other Hanford contractors and offsite vendors. Scheduling must be well planned and executed to obtain the desired improvements in productivity at appropriate intervals.

Specific tasks and schedules are listed in the Appendix for accomplishing 333-tube charge-discharge by the start of FY84. This would be followed by achieving 500-tube charge-discharges by the start of FY86. The estimated cost of this effort is very subjective because of the many unknowns involved in this plan. However, the tasks itemized in the Appendix are estimated to cost $\$ 14$ million over the scheduled period. The cost breakdown includes $\$ 175$ thousand for FY82, assuming the work starts by July 1982, then $\$ 4.68$ million for $F Y 83, \$ 5.37$ million for FY84, and $\$ 4.04$ million in FY85.

At the completion of this program, the reactor availability could be increased by as much as 33 days per year. Further, all of the major equipment involved in charge-discharge will be either new or improved and adequately maintained. This equipment should provide many aoditional years of reliable operation at the increased charge rates. This increased productivity would result in longer continuous operating periods, providing additional benefits in fuel handling and shipping requirements. 
APPENDIX

TASK BREAKDOWN 
APPENDIX

TASK BREAKDOWN

The following breakdowns are provided as an abbreviated summary of the tasks necessary to accomplish the recommendations contained in this report. Tasks being undertaken in the Restoration Program are included here for those items which impact the fuel flow path.

\section{TASK SCOPE STATEMENTS}

Unirradiated Fuel Storage

A. Evaluate options available

B. Select option for 330 tube discharges

C. Select option for 500 tube discharges

D. Implement $B$ per schedule required

E. Initiate action to achieve $C$

1. Purchase additional monotubes

2. Implement $300 \mathrm{~A}$ storage and shipping

3. Prepare procedure documents and implement training programs

Improve Communications Systems (Restoration Program)

A. Evaluate previous studies and design changes

B. Evaluate efforts presently underway

C. Implement appropriate action to complete modifications

D. Provide schedule for implementation and completion

Elevator Maintenance and Upgrading (Restoration Program)

A. Review ongoing efforts

B. Implement supplemental improvement programs if required

C. Prepare revised maintenance and precheck procedures and implement these procedures

D. Integrate schedule with all other tasks 
Crane Upgrade and Maintenance (Restoration Program)
A. Review ongoing efforts
B. Implement supplemental improvement programs if required
C. Prepare revised maintenance and precheck procedures and implement these procedures
D. Integrate schedule with all other tasks
Monotube Loader Upgrade

A. Evaluate options for improvement

B. Initiate programs to achieve improvements

C. Integrate programs into overall productivity improvement schedule

D. Prepare revised maintenance and precheck procedures and implement

Monotube Loader Replacement
A. Initiate conceptual design study
B. Obtain cost estimates and schedules
C. Evaluate potential vendors
D. Establish schedule and design basis
E. Implement procurement
F. Track fabrication and testing
G. Integrate task into overall productivity improvement program
Monotube Additional Storage and Loading

A. Evaluate unirradiated fuel storage options

B. Implement efforts into program plan and schedule

C. Evaluate overall impact on charging oprations

D. Establish programmatic plan and schedule

Monotube Dryer

A. Evaluate conceptual designs

B. Select best design

C. Establish engineering effort or vendor development

D. Integrate task into overall productivity improvement program schedule

E. Implement interim resolution of problem 


\section{Charge Machine Upgrade}

A. Review control system upgrade and revise as required

B. Establish balance of machine improvements required or desired

C. Establish schedule and engineering tasks to implement $B$ Charge Machine Replacement

A. Provide schedule and cost for redesign effort

B. Implement redesign program

C. Integrate all tasks into overall productivity improvement program Process Tube Cap Improvement

A. Initiate study on cap redesign options

B. Develop cost estimates and benefits

C. Implement program if appropriate

D. Evaluate alternative or interim improvements using existing cap design Process Tube cap Installer

A. Review ongoing improvement programs

B. Redirect or supplement efforts as required

C. Establish long-term program requirements, schedule and costs

D. Implement programmatic efforts to comply, with schedule and costs

Tip-0ff Upgrade

A. Review ongoing improvement programs

B. Redirect or supplement efforts as required

C. Establish long-term program requirements, schedule and costs

D. Implement programatic efforts to comply with schedule and costs

\section{Robotic Systems for C\&D Elevators}

A. Complete conceptual design

B. Evaluate impacts of design on associated systems

C. Complete engineering design

D. Vendor development

E. Purchase and testing

$F$. Procurement of associated systems

$G$. Implementation into $C-D$ system 
Improve Air Wrenches

Provide improved tool design

Improve Breaker Bars

Provide improved tool design

Improve Torque Wrenches

Provide improved tool design

Relocate Air Lines On Elevators

Implement design change

Demineralized Water Conservation

A. Evaluate options

B. Select plan

C. Implement engineering efforts if requirea

D. Schedule modifications as required

E. Integrate into overall operating schedule

Radiation Shielding

A. Evaluate elevator shielding concepts

B. Select and implement $A$

C. Evaluate balance of plant or decontamination opportunities

D. Implement through design changes as required

Fast Cart Upgrade

A. Review failure data

B. Evaluate possible improvements

C. Select engineering efforts and implement design changes where possible

Fast Cart Replacement

A. Review options for replacement sysțems

B. Select best option

C. Implement conceptual design and vendor contact

D. Establish vendor contract and test plan

A. 4 
E. Develop schedule and cost estimate

$F$. Integrate $E$ into overall productivity improvement plan

\section{Canister Redesign}
A. Evaluate conceptual designs and long-term programmatic requirements
B. Develop cost-benefits for redesign
C. Implement redesign
D. Prepare work procedures, retooling, requirements
E. Integrate modifications into productivity improvement schedule
Basket Replacement/Upgrade
A. Assess basket requirements related to productivity requirements
B. Develop requirement schedule and implement as required
C. Integrate basket replacement plan into productivity improvement program Reorganize Basin Operations
A. Prepare plan for work reorganization
B. Obtain necessary approvals
C. Implement training program
D. Implement basin operations
E. Follow up modifications as required to streamline procedures
Relocate Basin Canning Operatons
A. Evaluate existing procedures
B. Prepare plan for canning and capping operations
C. Integrate into overall productivity improvement program
D. Prepare documents and obtain approvals
E. Implement relocation of operations
F. Follow up modifications to procedures and practices
Improve Basin Ventilation
A. Evaluate plans underway or implemented
B. Prepare and implement alternate plans if required 
Reduce Fuel Damage

A. Evaluate extent, origin, and duration of present problem

B. Evaluate proposed solutions and benefits

C. Implement solutions if practical

Canister Test

A. Prepare development test document

B. Test new fuel in canisters in cubicle

C. Evaluate results of test

D. Implement direct canning plan into productivity improvement program if applicable

We 11 Car and Cask Upgrade

A. Evaluate plans and programs underway

B. Establish alternative or backup solutions

C. Assist in implementation of $A$ and/or $B$

D. Implement plans to PI program

Additional Well Cars and Casks

A. Evaluate results of planned efforts

B. Implement plans for additional cars and casks if required Recanning Operations ( $\mathrm{N}$-Basin)

A. Evaluate the impact of recanning on the PI program

B. Aavise on recanning approach and location of operation

C. Recommend utilization plans for cranes and manpower

Recanning Operatons (KE-Basin)

A. Evaluate the impact of recanning on the PI program

B. Recommend on procedural integration with the PI program activities Removal of Equipment From $\mathrm{N}$-Basin

A. Prepare list of material to be removed

B. Prepare documents and schedule for removal

C. Implement removal operations 


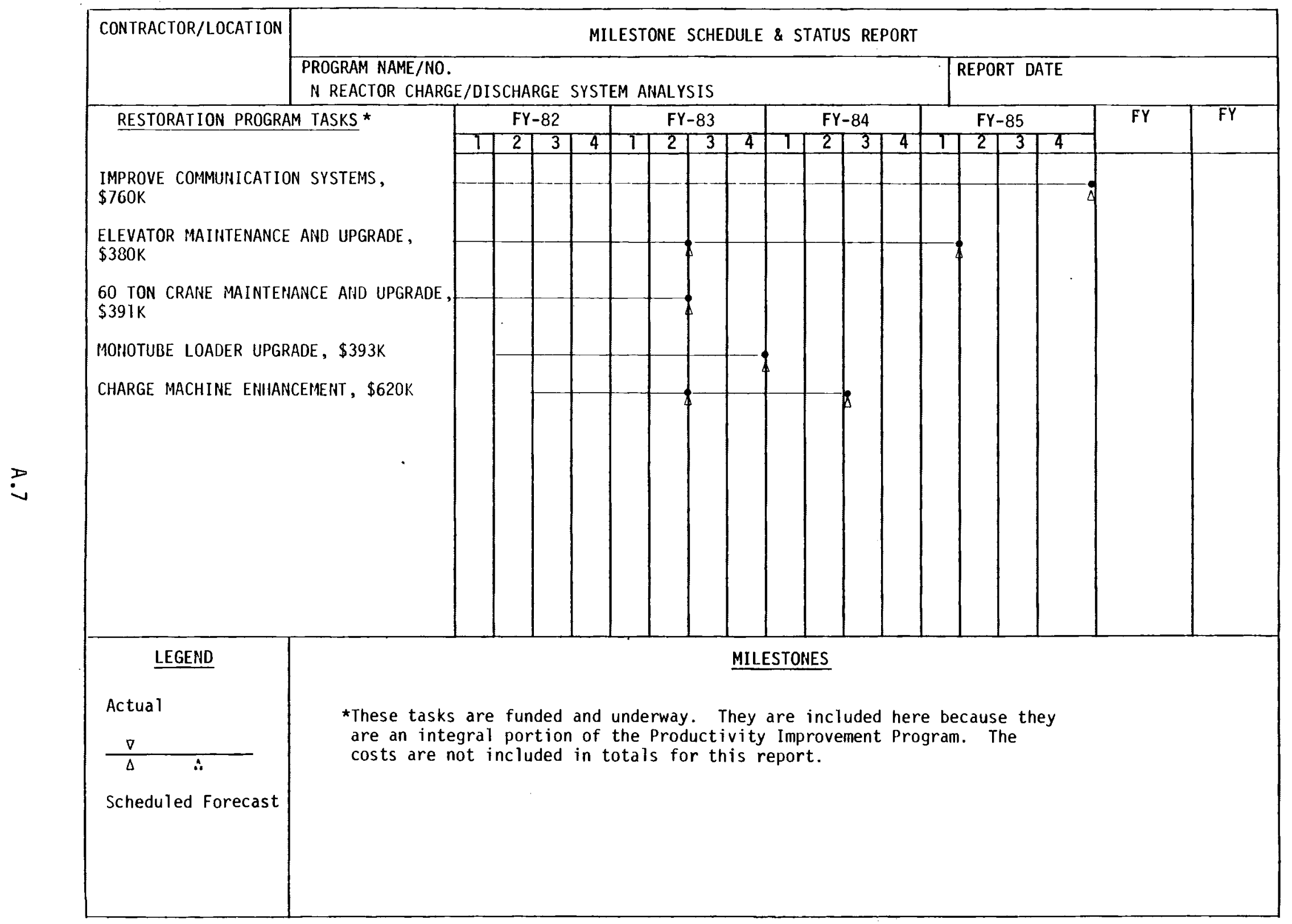




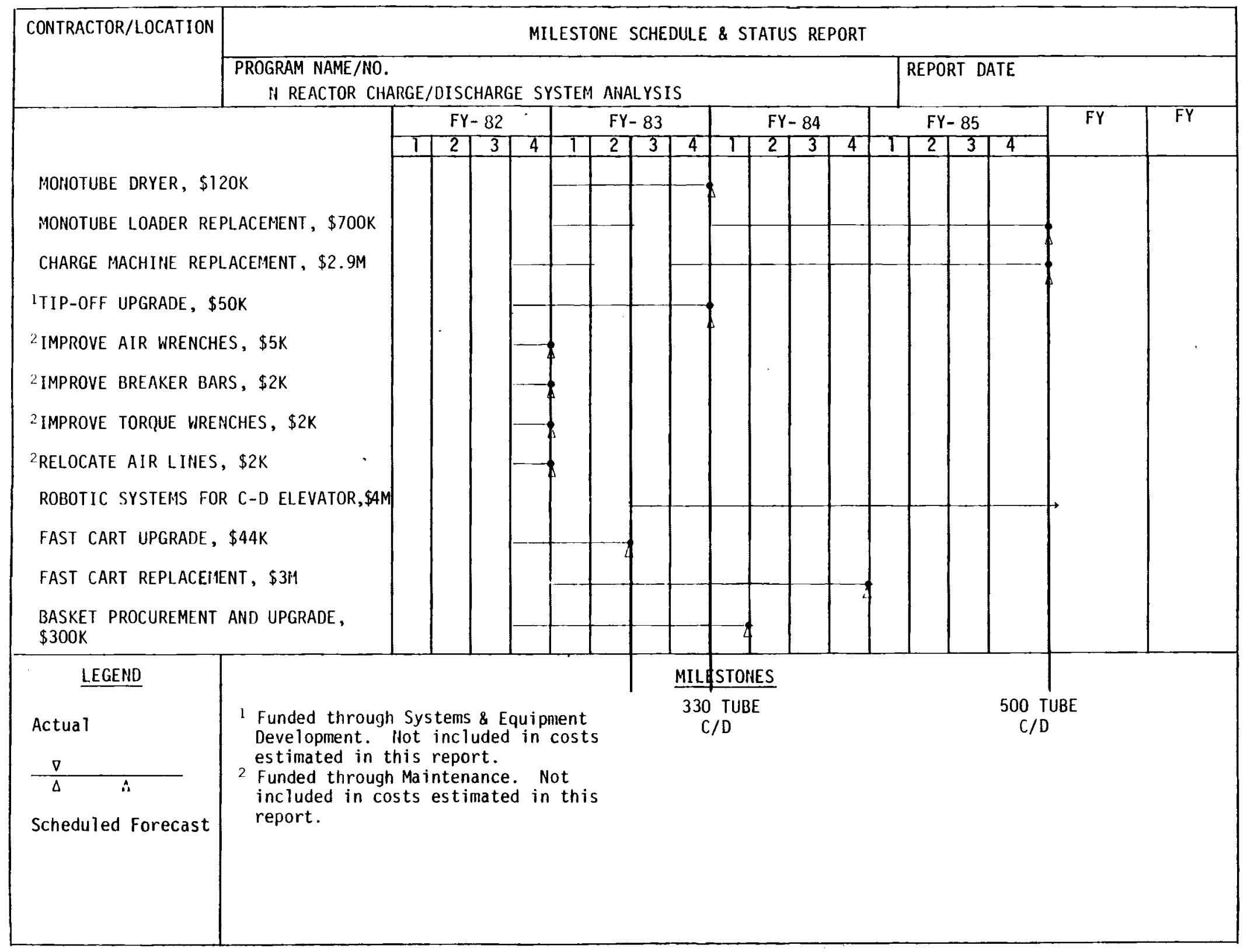




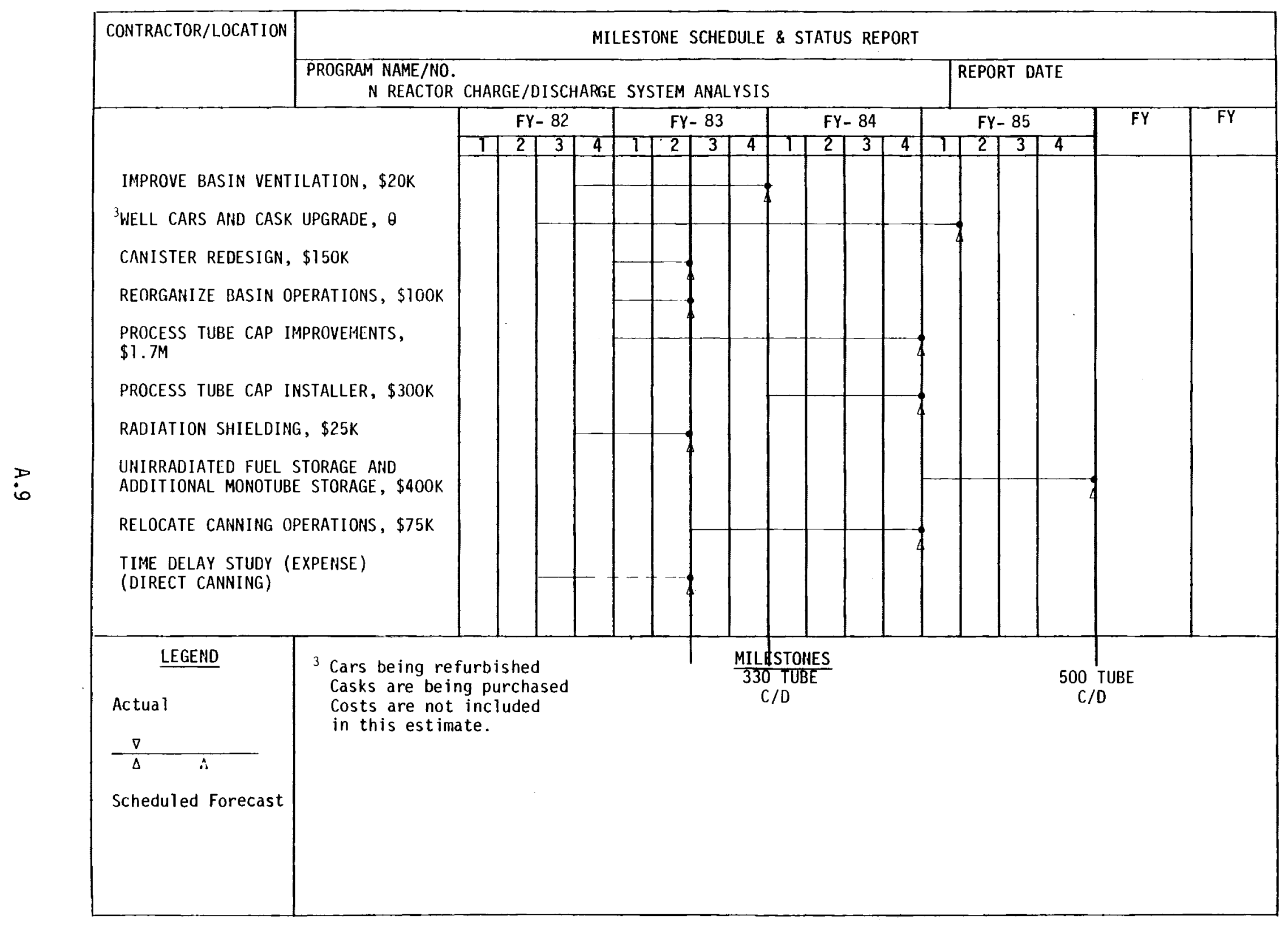




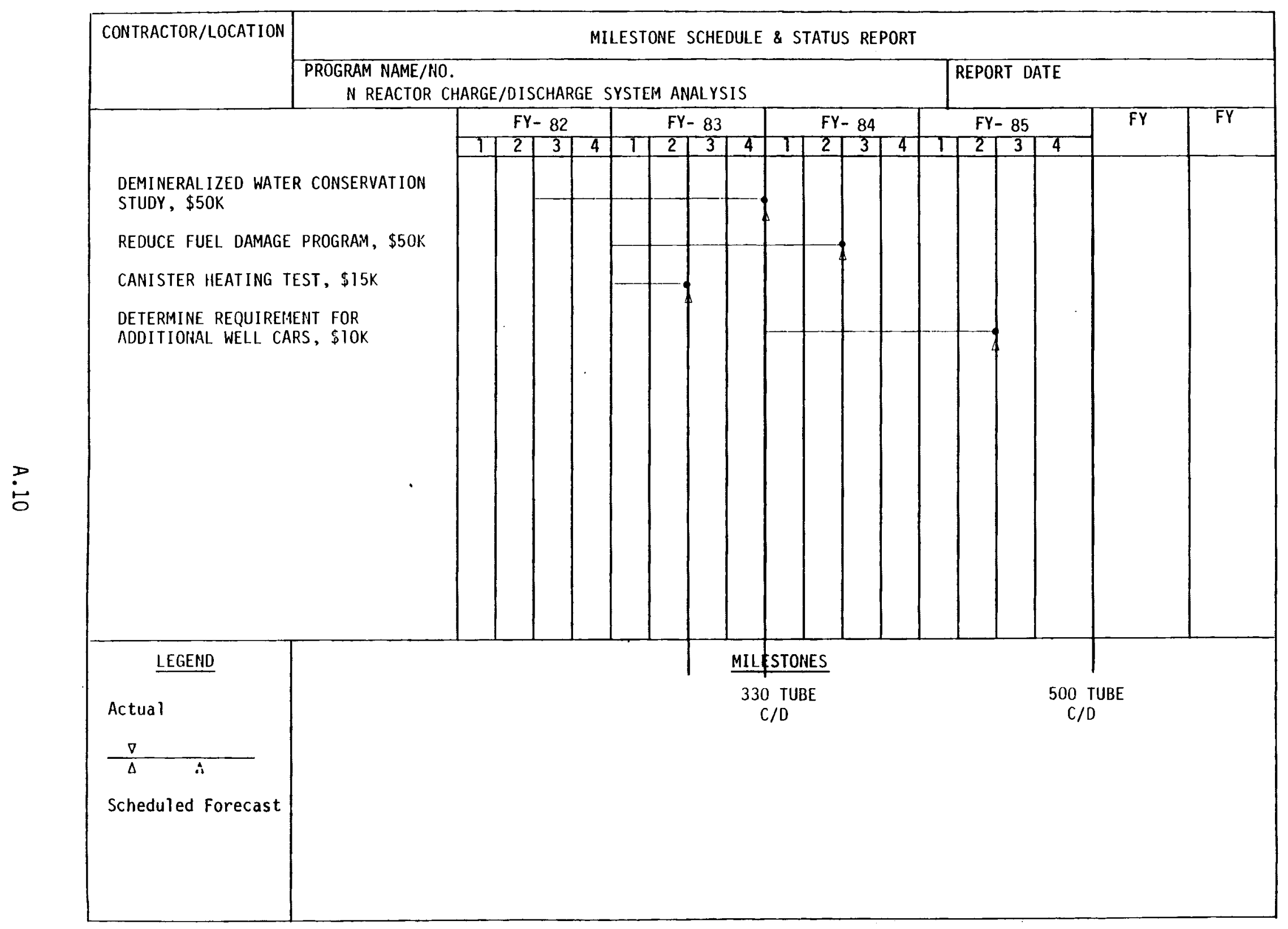




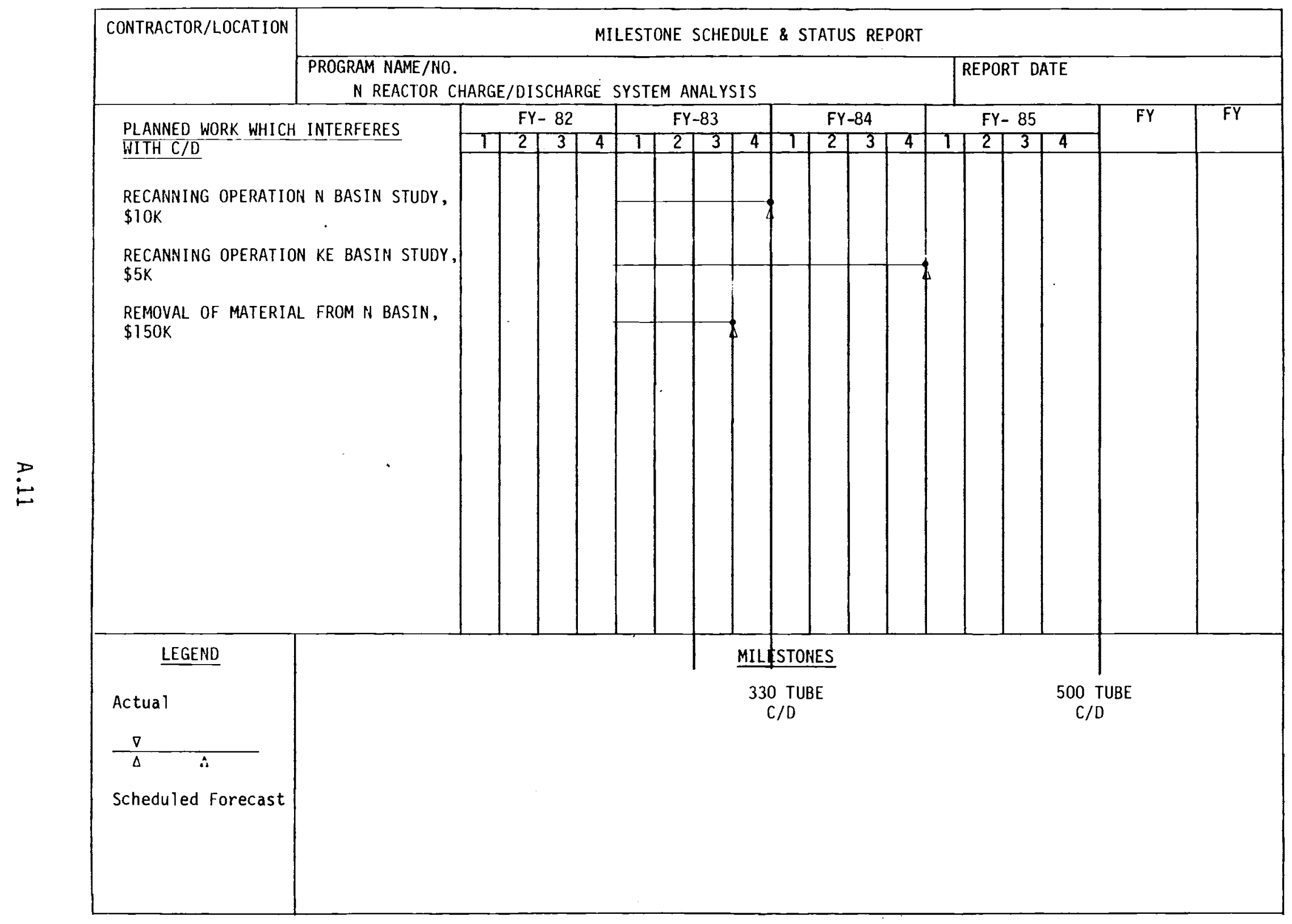




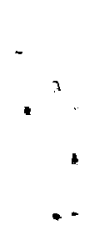


PNL-4314

UC -2

\section{DISTRIBUTION}

No. of

Copies

OFFSITE

27 DOE Technical Information Center

ONSITE

DOE Richland Operations Office

H. E. Ransom

22 UNC Nuclear Industries

D. E. Anderson

G. L. Erickson

J. E. Kaveckis

W. E. B. Lander (15)

E. E. Leitz (4)
No. of

Copies

25 Pacific Northwest Laboratory

M. C. C. Bampton

W. W. Laity

M. A. Lind

W. V. Loscutoff

G. D. Marr

J. F. Nesbitt

L. T. Pederson

A. M. Sutey

R. D. Tokarz (10)

Publishing Coordination (2)

Technical Information (5) 


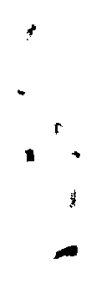

